\title{
Mean circulation of the Coral Sea
}

\author{
William S. Kessler ${ }^{1}$ and Sophie Cravatte ${ }^{2,3}$ \\ Received 20 May 2013; revised 19 September 2013; accepted 15 October 2013; published 3 December 2013.
}

[1] The mean absolute geostrophic circulation of the Coral Sea is constructed from climatological hydrographic data referenced to a $1000 \mathrm{~m}$ velocity field derived from Argo float drift. Two branches of the South Equatorial Current (SEC) enter the Coral Sea between New Caledonia and the Solomon Islands: the broad, upper thermocline North Vanuatu Jet (NVJ), and the narrow North Caledonian Jet (NCJ) extending to at least $1500 \mathrm{~m}$. Most of this incoming flow leaves to the Solomon Sea. Four distinct pathways through the Coral Sea are traced by their water properties: (1) The NCJ crosses the Sea to the coast of Australia and turns north at densities sigma 25-27.4 as the main source of the Gulf of Papua (GPC) western boundary current, eventually feeding the New Guinea Coastal Undercurrent; (2) part of the shallow NVJ turns into the Solomon Sea in midbasin, carrying high-salinity water above sigma 25.5; (3) another part of the NVJ continues to Australia, then turns north to join the GPC, extending it to the surface; (4) a shallow finger of NVJ water, traced by low oxygen above sigma 25, turns south along the coast, beginning the East Australian Current (EAC) at $15^{\circ} \mathrm{S}$. Total transport from the Coral to the Tasman Sea is small and shallow; instead, most of the EAC is fed from south of New Caledonia, consistent with the Island Rule. However, large transport fractions occur in narrow jets close to coastlines and reefs and are not well sampled, precluding a quantitative estimate of meridional redistribution of the incoming SEC.

Citation: Kessler, W. S., and S. Cravatte (2013), Mean circulation of the Coral Sea, J. Geophys. Res. Oceans, 118, 6385-6410, doi:10.1002/2013JC009117.

\section{Introduction}

[2] Because it sits at a bifurcation where subtropical South Pacific waters split into equatorward and poleward branches, the Coral Sea has been the subject of organized surveys and analyses for more than 50 years. These studies have shown that the South Equatorial Current carries about $30 \mathrm{~Sv}$ west from the subtropical gyre into the Coral Sea between New Caledonia and the Solomon Islands (Figure 1). This flow bifurcates at or before the coast of Australia, turning north into the Solomon Sea toward the equator, and south into the East Australian Current, though the distribution has been controversial. The present work continues that effort, following its clearest predecessor [ $\mathrm{Qu}$ and Lindstrom, 2002]. Although the earlier findings are broadly confirmed here, the advent of the Argo float array [Roemmich et al., 2009] provides a new

\footnotetext{
${ }^{1}$ Pacific Marine Environmental Laboratory NOAA, Seattle, Washington, USA.

${ }^{2}$ IRD (Institut de Recherche pour le Développement), Nouméa, New Caledonia.

${ }^{3}$ Laboratoire d'Etudes en Géophysique et Océanographie Spatiale (LEGOS), Observatoire Midi-Pyrénées, Université de Toulouse/IRD/ CNRS/CNES, Toulouse CEDEX, France.

Corresponding author: W. S. Kessler, Pacific Marine Environmental Laboratory NOAA, 7600 Sand Point Way NE, Seattle, WA 98115, USA. (william.s.kessler@noaa.gov)

C2013 The Authors. Journal of Geophysical Research: Oceans published by Wiley on behalf of American Geophysical Union. 2169-9275/13/10.1002/2013JC009117
}

piece of information that resolves a critical shortcoming of previous works and makes the study worth revisiting: middepth trajectories that allow geostrophic velocities to be referenced. (In addition, Argo has approximately doubled the number of hydrographic profiles in the region.) Since it was apparent from very early on that the Coral Sea supports currents of great vertical extent [Wyrtki, 1962b; Huang and Qiu, 1998; Sokolov and Rintoul, 2000], the choice of appropriate reference level has been a principal focus of much previous work. The ability to specify absolute currents at the Argo parking depth also emphasizes the narrow, jet-like nature of much of the flow entering and crossing the Coral Sea, currents that previously could only be broadly delineated in compilations of in situ observations.

[3] Recently, the Coral Sea has become the object of renewed interest, partly in connection with tropical Pacific decadal variability theories. The meridional circulation transporting water masses from the southern subtropics to the equator largely transits through the Coral and Solomon Seas, thus an accurate description of the pathways and transformations of water masses in the Coral Sea is of great importance to tropical climate on the basin scale. A credible diagnosis of the Coral Sea circulation is also necessary to understand flows reaching the Tasman Sea from the subtropics [Hill et al., 2011]. In this context, the international research program SPICE (Southwest Pacific Ocean Circulation and Climate Experiment) [Ganachaud et al., 2007], has begun a series of focused observational efforts to describe specific current systems that are part of the Coral Sea circulation [Gourdeau et al., 2008; Ganachaud et al., 


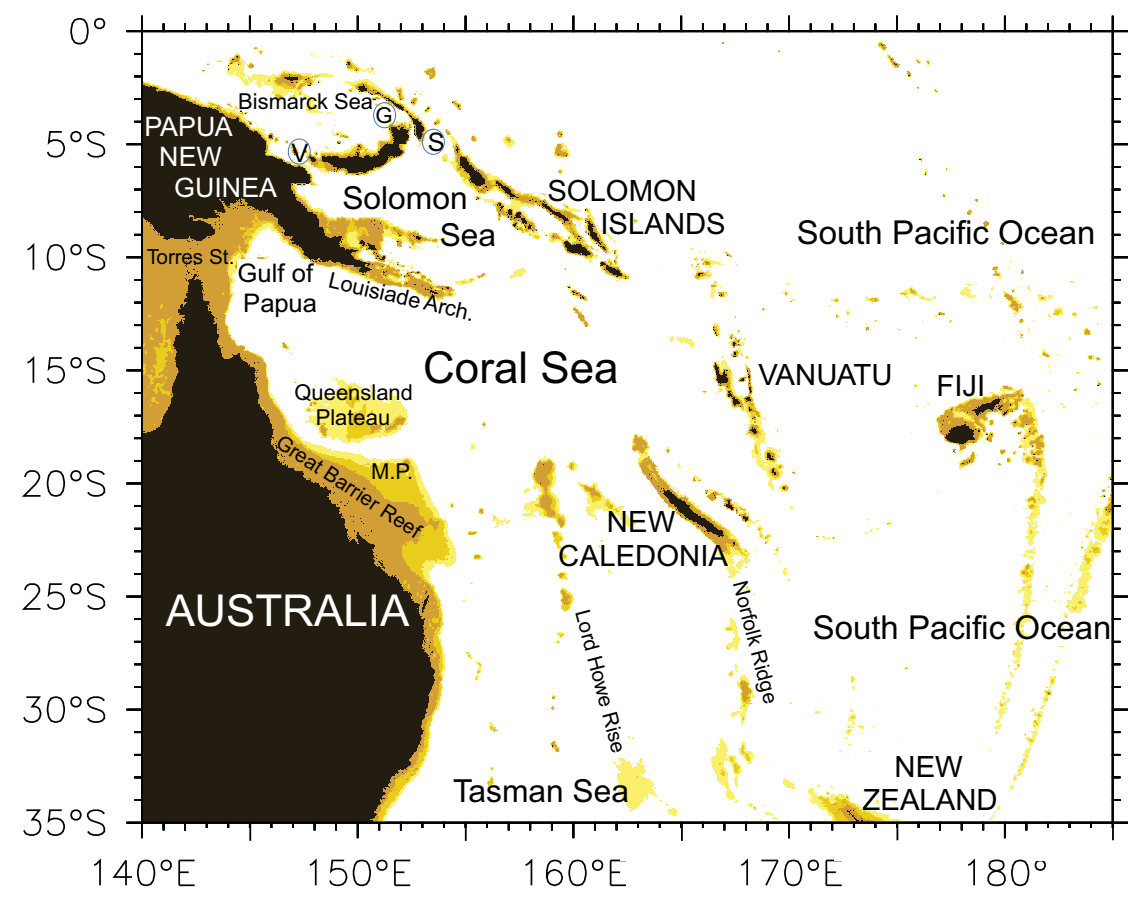

Figure 1. Reference map of the Coral Sea, showing features discussed in the text. Brown shading shows shallow bathymetry at depths of 100, 500, and $1000 \mathrm{~m}$. Names of countries are in upper case. "M.P." indicates the Marion Plateau near $20^{\circ} \mathrm{S}, 151^{\circ} \mathrm{E}$, and circled "V," "S," and "G" abbreviate Vitiaz and Solomon Straits, and St. George's Channel, respectively.

2008; Gasparin et al., 2011; Cravatte et al., 2011; Chroukroun et al., 2010; Hristova and Kessler, 2012; Gasparin et al., 2012; Davis et al., 2012]. To place this reinvigorated work on the Coral Sea into its historical context, section 1.1 below reviews key papers of the 1960s-1980s interpreting the circulation using in situ hydrographic observations. Many of the issues identified by previous researchers continue to be open topics today.

\subsection{Analyses of Coral Sea Cruise Data: The Evolution of Ideas}

[4] Early work in the Coral Sea identified issues that continue to be incompletely understood: the unusually thick currents and their subsurface maxima, the proper reference level to use for geostrophic calculations, and above all, the destination of water carried by the South Equatorial Current when it arrives at the coast of Australia.

[5] Although there had been scattered observations of Coral Sea hydrography during the 1950s [Rochford, 1960], the earliest organized surveys were conducted around 1960 by Office de la Recherche Scientifique et Technique d'Outre-Mer (ORSTOM) [Donguy et al., 1970] and Commonwealth Scientific and Industrial Research Organisation (CSIRO) [Wyrtki, 1962a, 1962b]. Wyrtki [1962b] attempted the first synthesis of these observations, calculating geostrophic flow relative to $1750 \mathrm{~m}$ and noting several features that remain valid: the large westward inflow to the Coral Sea between Vanuatu and the Solomon Islands, the great depth extent of many of the currents, and the general tendency to subsurface maxima of the westward currents. However, researchers at the time did not appreciate the possibility of narrow jets carrying substantial transport, and
Wyrtki's surveys apparently did not sample close enough to New Caledonia to observe the North Caledonian Jet, a narrow current at the northern tip of New Caledonia that carries about one-third the total Coral Sea inflow [Gourdeau et al., 2008]. Wyrtki [1962b] also stated that virtually all the westward inflow turned south into the East Australian Current, with almost no transport into the Solomon Sea (indeed, he made no attempt to calculate this transport); this has since been shown to be incorrect.

[6] Donguy et al. [1970] included additional surveys carried out by ORSTOM and also examined salinity on the isanostere $340 \mathrm{cl} /$ ton (close to sigma 24.5, at a depth of about $150 \mathrm{~m}$ in the Coral Sea, and near the subtropical salinity maximum layer). This field provided Donguy et al. an important clue that there was, in fact, a bifurcation of the inflow with a substantial transport northward into the Solomon Sea that could feed the equatorial current system. Like Wyrtki, however, Donguy et al. overestimated the importance of direct (frictional downwind) wind driving and assumed that the upper layer flow was entirely southeastward during austral summer when the trade winds are weak or reversed over the Solomon and northern Coral Seas. A full recognition of the key role of wind stress curl forcing and Sverdrup (vorticity) dynamics did not inform interpretation of the Coral Sea circulation until several decades later.

[7] Scully-Power [1973] diagnosed Nansen bottle data from a series of cruises by the Royal Australian Navy that attempted to systematically sample the Coral Sea during winter seasons of 1966-1971. Confirming Donguy et al. (and presaging conclusions here), Scully-Power found that most of the water entering the Coral Sea from the east 
between New Caledonia and the Solomon Islands (30 Sv geostrophic flow relative to $1500 \mathrm{~m}$ in his calculation) left the region to the north, with relatively little flow southward across $20^{\circ} \mathrm{S}$. Also like the present work, he found only weak circulation in the region west of New Caledonia to the coast of Australia, with the East Australian Current mainly fed by currents arriving from south of New Caledonia. Scully-Power described the northward western boundary current off the coast of north Queensland (the North Queensland Current), and suggested that the current turned offshore in the Gulf of Papua, but was unable to account for the very complex, small-scale flow in the Gulf itself.

[8] Thompson and Veronis [1980] attempted an inverse calculation [Wunsch, 1978] based on 24 bottle casts on a cruise describing a closed box from Australia along $30^{\circ} \mathrm{S}-$ $170^{\circ} \mathrm{E}$, then diagonally across the Coral Sea to Papua New Guinea. However, they found that they could not usefully describe the Coral-Tasman Sea connection, nor the EAC, for two reasons that continue to be impediments today: the narrow boundary currents carrying a large fraction of the transport that are not easily sampled by shipboard hydrography or Argo floats, and the extreme eddy variability, especially in the EAC.

[9] Andrews and Clegg [1989] invoked a baroclinic normal mode fit to partial conductivity-temperature-depth (CTD) profiles on a series of Coral Sea sections, using an inverse procedure to conserve total (top-to-bottom) volume flux and minimize abyssal velocities. The advantage of this approach is that it avoided the need to choose a reference level for geostrophic flow, but it also had the disadvantages of assuming (a) that observations from a single cruise represented the steady circulation; (b) that abyssal velocities were in fact small; and (c) that they had adequately sampled the narrow jets that we now know carry much of the transport. However, the method entirely missed the North Caledonian Jet (in fact, their scheme showed southeastward flow exiting the Coral Sea between Vanuatu and New Caledonia), and implied a total of $10 \mathrm{~Sv}$ of the entering $24 \mathrm{~Sv}$ ending up in the Tasman Sea.

[10] Two recent observational studies studied data from single cruises taking high-quality CTD profiles to at least $2000 \mathrm{~m}$ and came to opposite conclusions about the destination of the water flowing into the Coral Sea. Sokolov and Rintoul [2000] analyzed profiles from the World Ocean Circulation Experiment (WOCE) P11S cruise roughly along $154^{\circ} \mathrm{E}$ (that is, near the western boundary of the Coral Sea) in mid-1993. They found an astonishingly large transport of $54 \mathrm{~Sv}$ westward (relative to $2000 \mathrm{db}$ ) in the Coral Sea branch of the South Equatorial Current. Since this inflow can only exit eastward through the closed section itself, this implied that about $29 \mathrm{~Sv}$ flowed south in the East Australian Current into the Tasman Sea (with the remaining $25 \mathrm{~Sv}$ going into the Solomon Sea). On the other hand, Gasparin et al. [2012] studied a 2007 cruise that closed a triangular region touching New Caledonia, Papua New Guinea, and the Solomon Islands. An inversion based on this cruise's data showed a transport of $30 \mathrm{~Sv}$ entering the Coral Sea above $1300 \mathrm{db}$, of which $29 \mathrm{~Sv}$ turned north into the Solomon Sea [Gasparin et al., 2012]. Trying to resolve this discrepancy, Kessler and Cravatte [2013] used satellite altimetry to estimate that transients (mesoscale eddies and weak El Niño conditions) contributed about one-third the WOCE P11S westward transport. Considering the vigorous eddies revealed by altimetry, they concluded that a single cruise may not be a useful guide to the background circulation.

[11] These analyses of scattered hydrographic sections had established that substantial Coral Sea water turned north into the Solomon Sea. Tsuchiya [1981] put this observation into basin-wide context by showing that water making up the eastern equatorial Pacific thermostad $\left(13^{\circ} \mathrm{C}\right.$ water of relatively high salinity spanning the equator below the main thermocline) must come from the Tasman Sea. He traced a schematic pathway from the outcrop of the isanostere $160 \mathrm{cl} /$ ton (about sigma-theta 26.4) northeast of New Zealand, circulating around the subtropical gyre, through the Coral and Solomon Seas to the southern "Tsuchiya Jet" (Subsurface Countercurrent), whence it flowed east along about $5^{\circ} \mathrm{S}$. This suggested that the Coral Sea route was not just a regional phenomenon but a significant part of the makeup of the tropical Pacific.

[12] Tsuchiya's [1981] paper was the catalyst for the Western Equatorial Pacific Ocean Circulation Study (WEPOCS) experiments in the mid-1980s [Lindstrom et al., 1987; Butt and Lindstrom, 1994]. WEPOCS made detailed water property and velocity observations in the Solomon and Bismarck Seas and in the three straits that form its northern exits (Vitiaz and Solomon Straits, and St. George's Channel; Figure 1). They found [Tsuchiya et al., 1989; Fine et al., 1994] that the pathway to the equator followed the subsurface western boundary current in the Coral Sea observed by Church and Boland [1983] and Church [1987], now known as the Great Barrier Reef Undercurrent (GBRUC). Comparing water properties in the Solomon Sea and in the Equatorial Undercurrent, Tsuchiya et al. [1989] found that southern hemisphere water at the core of the Equatorial Undercurrent (near sigma 25) was fed both through Vitiaz St. and from the open Pacific north of New Ireland. Water comprising the thermostad below the EUC (near sigma 26.4) was clearly of Coral Sea origin.

\subsection{Motivation for the Present Study}

[13] $Q u$ and Lindstrom [2002, hereafter QL02] is the predecessor to the present work. They gridded available hydrographic data along isopycnals to produce mean fields of temperature, salinity, and oxygen on a $0.5^{\circ}$ by $0.5^{\circ}$ grid. To maximize the data coverage, QL02 computed dynamic height and geostrophic currents relative to $1200 \mathrm{~m}$, and presented a description of the circulation in approximately the same region as discussed here. They described the sheared current system across the region, with subsurface maxima of the westward South Equatorial Current and overlying eastward flow south of about $20^{\circ} \mathrm{S}$. They emphasized that the northward western boundary current feeding the Solomon Sea begins subsurface near $22^{\circ} \mathrm{S}$ and flows continuously into the NGCU. All these conclusions presage the present work and are largely confirmed here. There are two main differences in the approach taken here: first, we construct absolute velocity fields based on Argo trajectories to reference the geostrophic currents, which generally increases the estimated speeds and shows the jets to be narrower than could be resolved earlier; second, the accumulation of Argo temperature and salinity profiles has greatly increased the data coverage in the Coral Sea. Specific 
similarities and differences in the conclusions will be noted below.

[14] Consistent with earlier work [Tsuchiya, 1981; QL02], we will demonstrate the dynamical and property unity of the equatorward western boundary current beginning about $25^{\circ} \mathrm{S}$ and flowing continuously around the Gulf of Papua and into the Solomon Sea, accumulating mass and water properties from the zonal jets arriving from the east. It is thus confusing that this fundamental piece of the basin-wide circulation has been given a series of four local names. From $19^{\circ} \mathrm{S}$ to about $15^{\circ} \mathrm{S}$ along the coast of Australia where the northward flow is subsurface, it has been called the Great Barrier Reef Undercurrent (GBRUC) [Church and Boland, 1983]. From its surfacing to Torres St. it is usually called the North Queensland Current (NQC) [QL02; Ridgway and Dunn, 2003]. The eastward limb along the south coast of Papua New Guinea has been referred to as the Hiri Current [Burrage, 1993; Schiller et al., 2009; Cravatte et al., 2011], but its eastern part along the Louisiade Archipelago has also been called the New Guinea Coastal Undercurrent [Sokolov and Rintoul, 2000]. The connections and boundaries between these various elements have never been clear. Considering the continuous nature of this boundary current and its water properties, and its important role in the general circulation of the South Pacific, it would make sense to describe it with a single name. Consistent with modern oceanographic practice of geographically descriptive nomenclature, a recently proposed name is the "Gulf of Papua Current" [SPICE Community, 2012]. At the point where the boundary current turns sharply into the Solomon Sea and joins with substantial inflow from the interior ocean (section 4), it would then make sense for the name to change, and New Guinea Coastal Undercurrent (NGCU) is well established for this part of the flow [Tsuchiya et al., 1989]. In the following, we will use "Gulf of Papua Current" (GPC) to refer to this boundary current within the Coral Sea, noting the earlier names as appropriate.

[15] This paper has the following structure. Section 2 describes the data and methods used, referring to the Appendix for details. Section 3 discusses the vertically integrated circulation, introducing the Island Rule as a dynamical framework and comparing its predictions with the observed transports. Section 4 describes the baroclinic velocity structure and its role in advecting water masses and producing the observed property patterns. Section 5 discusses the western boundary currents of the Coral Sea and their bifurcation. Section 6 considers the results in light of the dynamical ideas previously explored and those more modern. We conclude with a discussion of the remaining open questions of the Coral Sea circulation.

\section{Data and Methods}

[16] The foundation of this paper is estimating the absolute velocity at $1000 \mathrm{~m}$ from drift trajectories of Argo floats, then using that as a level of known motion to reference geostrophic shear from the CARS (CSIRO Atlas of Regional Seas) Atlas [Dunn and Ridgway, 2002; Ridgway et al., 2002] (http://www.cmar.csiro.au/cars), giving a field of three-dimensional mean absolute geostrophic velocity in the Coral Sea. Float motion was extracted from the subsur-

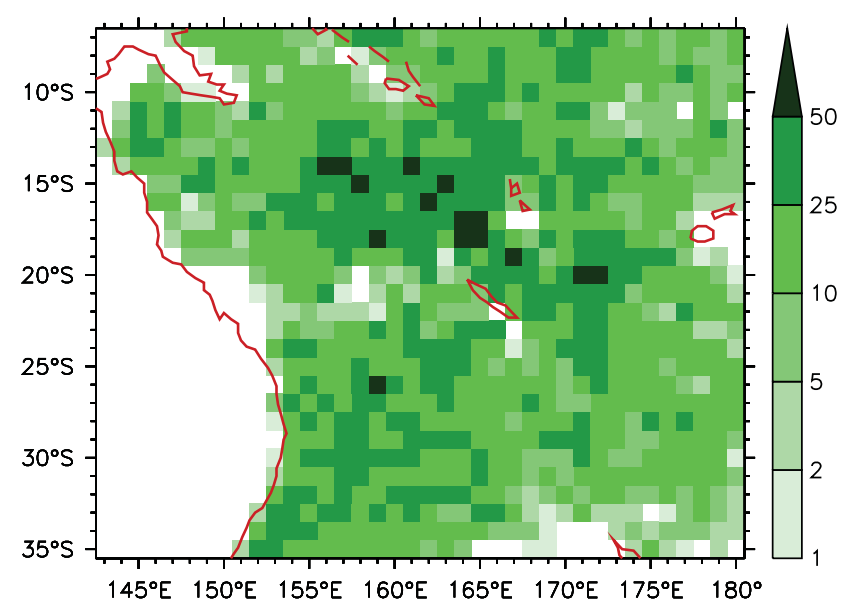

Figure 2. The number of Argo drift velocity samples in each $1^{\circ}$ by $1^{\circ}$ bin.

face drift of 208 quality-controlled floats in the region $140^{\circ} \mathrm{E}-180^{\circ} \mathrm{E}, 30^{\circ} \mathrm{S}-7^{\circ} \mathrm{S}$ through May 2011 , and objectively mapped. Figure 2 shows that the sampling by these floats was densest along a route from east of New Caledonia into the central Coral Sea; we will see below that this is a principal pathway of subthermocline flow in the region. The quality control, treatment of floats with varied parking depths, estimation of surface and ascent/descent times and drifts, and the objective mapping procedures are discussed in the Appendix. The resulting mapped $1000 \mathrm{~m}$ currents are shown in Figure 3a. In a few places where the bottom is shallower than $1000 \mathrm{~m}$, and thus not sampled by Argo float drift, we chose to reference geostrophic velocities at the bottom; consequences of this choice for specific regions are mentioned in the text.

[17] Consistency might suggest using dynamic height and geostrophic shear from the same Argo floats that provide the trajectory information, which would have the advantage that the times of the profiles would be the same as those of the velocities. This could be done either profile by profile or more generally by using climatology such as the Argo Atlas [Roemmich and Gilson, 2009]. However, Argo shear provides timely gradients only in the alongtrack direction (namely it only gives the cross-track geostrophic velocity component), which is less useful for the present purpose since by definition the velocity direction sampled by the float trajectories is along track. A further problem occurs in the western boundary currents where the cross-shore density field resolution provided by existing Argo sampling is inadequate to define the sharp gradients. We also found that the Argo Atlas, which is intended for studies of large-scale phenomena, had weak isopycnal slopes along the western boundary where they are known to be steep, with consequent weak geostrophic shear. The CARS climatology, on the other hand, incorporates many Australian nearshore profiles (and the 2009 version we used includes Argo profile data through about 2008) and gives apparently more realistic geostrophic cross-shore shears. As a result of this testing, we concluded that the CARS fields gave a better depiction of the cross-shore property gradients and alongshore geostrophic shear than the Argo Atlas, especially for the western boundary 


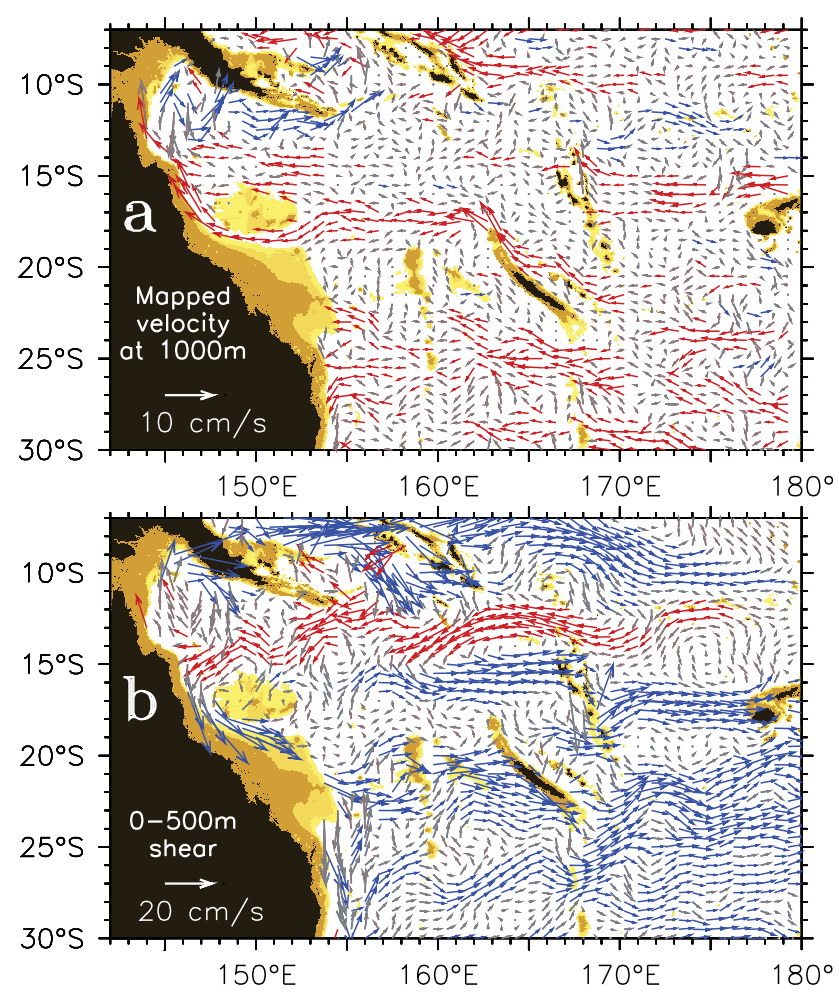

Figure 3. (a) Mapped Argo drift velocity at $1000 \mathrm{~m}$. The scale vector is at bottom left, and vectors with zonal component larger than $1.5 \mathrm{~cm} \mathrm{~s}^{-1}$ are colored by their zonal component: red for westward, blue for eastward. (b) CARS geostrophic velocity at the surface relative to 500 $\mathrm{m}$. The coloring is the same as for the top plot, except it begins for magnitudes greater than $4 \mathrm{~cm} \mathrm{~s}^{-1}$. Bathymetry as in Figure 1.

currents. However, the disadvantage of using CARS is that the Argo parking-depth velocities cover primarily the period 2005-2010, while the CARS geostrophic shear spans a longer period, thus mixing temporal and spatial signatures. It is not possible to precisely specify the time distribution of Coral Sea profile data that went into the CARS compilation, but about half of it comes from the Argo floats, and the remainder going back primarily to the 1980 s (J. Dunn, personal communication, 2012).

[18] As is typical of many historical hydrographic surveys, the sampling in CARS decreases greatly below 1000 $\mathrm{m}$ depth. In the Coral Sea, about half as many samples make up CARS fields at $1500 \mathrm{~m}$ as near the surface, and about a third as many at $2000 \mathrm{~m}$. For this reason, we have less confidence in geostrophic shears estimated from CARS below $1000 \mathrm{~m}$, and have focused on the 0-1000 m flows deduced from our referenced product. The only exception is along the western boundary, where the CARS deep sampling is somewhat more complete and the structures below $1000 \mathrm{~m}$ are of great interest.

[19] On the other hand, the data remains too sparse, and the gridding algorithm used to construct the CARS fields appears too coarse, to adequately describe nearshore shears in a few crucial locations, most notably around the tip of the Louisiade Archipelago at the southeast tip of Papua New Guinea (Figure 1). Other studies using glider data have shown sharp property gradients and large transports very close (less than $10 \mathrm{~km}$ ) to the reef line as the NGCU turns sharply around the island chain [Gasparin et al., 2012; Davis et al., 2012]. We attempted to embed the Davis et al. glider fields near the Louisiades into the CARS grid, but concluded that this could not be usefully accomplished, primarily because the glider data only extends to $700 \mathrm{~m}$. The unfortunate consequence of this failure is that we do not have confidence in a critical number: the northward transport from the Coral into the Solomon Sea, and this important topic is left for future study.

[20] Although it would have been desirable to extend the study into the Solomon Sea and thus be able to describe the equatorward pathway more fully, we found that Argo sampling inside the Solomon Sea was insufficient to describe the velocity structure at $1000 \mathrm{~m}$. A total of 12 Argo floats had entered the Solomon Sea through May 2011: four westward through Solomon St., six northward in the NGCU close to the Louisiade Chain, and two northward in the open water east of the Louisiades. Only one of these has left the Solomon Sea (through Vitiaz St.), and three appear to have died on reefs. The rest have spent months or years wandering irregularly in the central basin without any consistent pattern of motion. Although formally the objective mapping produced a solution, it shows abrupt changes of direction with strong velocity convergences at $1000 \mathrm{~m}$. Apparently, this represents time variability and in our judgment is not realistic or useful; we therefore forwent a description of the velocity north of $9^{\circ} \mathrm{S}$ in the Solomon Sea.

[21] The resulting three-dimensional flow field of referenced geostrophic currents shows that there is no appropriate "level of no motion" in the Coral Sea. Current magnitudes resulting from this method were at least a few $\mathrm{cm} \mathrm{s}^{-1}$ down to $2000 \mathrm{~m}$ in the zonal jets and western boundary currents.

\section{Vertically Integrated Transports and the Island Rule}

\subsection{Introduction: Island Rule}

[22] The simplest dynamical picture of the flow through the Coral Sea is the linear, wind-driven Island Rule stream function [Godfrey, 1989]. The Island Rule is a generalized Sverdrup circulation taking into account the blocking effects of the large islands that are a first-order feature of the southwest Pacific; it also predicts the western boundary currents implied by the interior transports. While Sverdrup dynamics are a simplification, in particular by representing only a vertical integral, assuming that a few years of sampling adequately represents the mean, and that the bottom is flat (which is far from the case in this region [Couvelard et al., 2008]), they have proven remarkably robust in predicting the volume transport and flow structures in many parts of the world ocean. The Island Rule puts the regional circulation into basin and global context, shows how Coral Sea circulation is shaped by basin-scale winds, and also shows how local wind features-modified by the high islands-produce specific regional currents. It provides a linear first-guess hypothesis whose inconsistencies with observations point to where nonlinear or topographic effects might be important, and we bring those out in the 
sections below. We will therefore describe the predicted Island Rule circulation, using this to introduce the wind forcing that drives the Coral Sea currents, and also as a framework for discussing the currents and transports themselves. In later sections, we discuss elements of the observed circulation that diverge from this simple picture, as well as the baroclinic structure that is not specified by the vertically integrated Island Rule.

[23] The Island Rule has been thoroughly discussed in several publications [Godfrey, 1989; Wajsowicz, 1993; Pedlosky et al., 1997; Firing et al., 1999], and the particular solution shown here is detailed in the Appendix of Qiu et al. [2009], so here we only mention the specific aspects necessary for the present story.

[24] Briefly, east of island barriers, the volume transport stream function is found from the Sverdrup relation (i.e., proportional to the westward integral of the wind stress curl from a constant eastern boundary condition). At an island barrier, where the Sverdrup integration cannot proceed, the Island Rule determines the value of the stream function around its coast; in practice this value is dominated by the meridional average of the Sverdrup transport east of the island. Thus, while the initial Sverdrup integration is conducted at each latitude independently, the island value links the Sverdrup values over the latitude range of the island. Circum-island winds also contribute to the island stream function, though this is usually a small term, even for the large islands of Australia and New Zealand [Qiu et al., 2009]. Note that it is important to include New Zealand in the calculation of the Island Rule stream function for Australia, since the islands overlap in latitude [Godfrey, 1989]; in the present calculation, New Zealand increases the value of the stream function at Australia by about $8 \%$. Transport between any two islands is given by the stream function difference between them (including South America, here taken as zero).

[25] The stream function is constant around the island's coast, so any meridional gradients that might occur to its east are suppressed to its west, where the Sverdrup westward integration proceeds to the next island. Thus, all the Sverdrup zonal transport east of an island is concentrated into jets emanating from the island's tips, and we expect relatively quiet regions extending west from the island.

[26] The inferred western boundary current along an island's coast is the difference between the Island Rule stream function value at the coast and the Sverdrup stream function immediately to its east. In most cases, the meridional averaging that produces the Island Rule value implies that at some latitude on the island's east coast the coastal and offshore stream functions will be equal, and thus the boundary current there will be zero; i.e., it bifurcates. Thus, in general the net meridional transport of the western boundary transport at an island is small; typically, we find a simple split of the incoming transport, in some cases partly weighted to the north or south of the island.

\subsection{Uncertainties of the Island Rule Calculation}

[27] It is worth noting the problems and uncertainties in a practical implementation of the Island Rule for this region. South Pacific islands commonly have offshore island chains separated by channels (Vanuatu) or reef systems that greatly extend their effective length (New Cale-

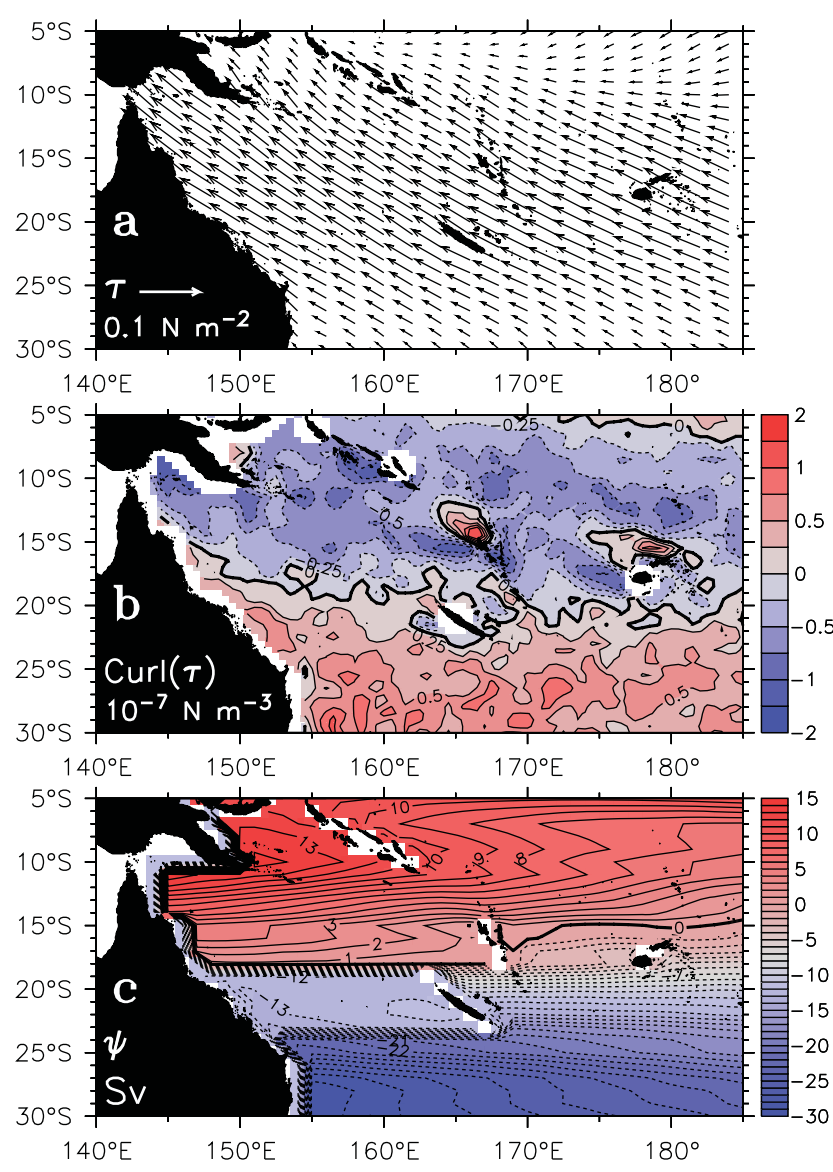

Figure 4. (a) Mean wind stress vectors from ERS winds during 1991-2000 (scale vector at bottom left); (b) Mean wind stress curl $\left(10^{-7} \mathrm{~N} \mathrm{~m}^{-3}\right)$ based on the winds in Figure $4 \mathrm{a}$; (c) Sverdrup transport stream function (Sv) calculated from Godfrey's Island Rule and the wind stress curl field in Figure $4 b$.

donia). The resulting - debatable - choices of island length, which may be constrained by the resolution of the gridded wind product used, have a significant effect on the solution [e.g., Couvelard et al., 2008]. Even a $50 \mathrm{~km}$ span difference can change the estimated stream function at the island by up to a few Sv. These uncertainties mean, for example, that the bifurcation streamline of the South Equatorial Current at the coast of Australia can appear either north or south of New Caledonia for seemingly slight changes in the assumptions. Thus, we hesitate to ascribe precision closer than a few Sv to Island Rule-estimated values of transport between islands.

[28] The Island Rule provides no solution inside the Gulf of Papua, which is shadowed from westward-propagating long Rossby waves, and where linear Sverdrup dynamics cannot represent the expected western boundary overshoot (Bryan [1963]; Veronis [1966]; Pedlosky [1987, see his sections 5.6 and 5.7]). For the solution shown in Figure 4c, we have simply assumed that the land mass of New Guinea fills the Gulf north of $10^{\circ} \mathrm{S}$, and thereby forced the implied boundary current to flow directly from the coast of Australia along the southern edge of the Louisiade Archipelago. Similarly, the Island Rule does not encompass the dynamics that cause the EAC to separate from the coast, 
break into eddies, and recirculate [Godfrey and Golding, 1981]. A second difficulty is that the Island Rule assumes that an "island" is far enough east of the western boundary layer of the next coast to its west that it can be considered independent. That assumption may well not be accurate for $160 \mathrm{~km}$ wide Solomon Strait, so the estimate of Solomon Island stream function shown in Figure $4 \mathrm{c}$ is open to question.

[29] Nevertheless, given the robustness of the Sverdrup circulation in much of the world ocean, the importance of the islands in determining the South Pacific circulation, and the clarity of the Island Rule's depiction both of the blocking effects of the islands and the role of specific features in the regional wind stress curl, it is well worthwhile to examine this picture of the vertically averaged wind-driven currents.

\subsection{Island Rule Results}

[30] Mean wind stress over the Coral Sea (Figure 4a) is dominated by southeasterly trade winds whose maximum is roughly along $20^{\circ} \mathrm{S}$ : from south of Fiji, just north of New Caledonia, then trending slightly north to Australia (the zero wind stress curl line in Figure 4b). Mean zonal wind stress is much weaker in the South Pacific Convergence Zone (SPCZ) along $6^{\circ}-10^{\circ} \mathrm{S}$. The resulting negative (upwelling) wind stress curl that overlies the northern Coral Sea lifts the thermocline toward the north (Figure 5a) to a peak near $10^{\circ} \mathrm{S}$ (not shown); the resulting slopes north and south from this peak intensify westward gyre flow from about $10^{\circ}-14^{\circ} \mathrm{S}$ and also produce the eastward South Equatorial Countercurrent north of the peak along $7^{\circ}-9^{\circ} \mathrm{S}$ (Figure 3c, and Chen and Qiu [2004]). Broadly speaking, this entire pattern moves with the sun: displaced about $5^{\circ}$ northward in southern winter and southward in southern summer. The high mountains of Fiji and Vanuatu, and to a lesser extent New Caledonia, create wind speed minima in the lee to the northwest of these islands (Figure 4a), resulting in wake dipoles of positive and negative curl (Figure $4 \mathrm{~b}$ ), similar to features that have been noted behind other mid-Ocean islands [Chelton et al., 2004]. These dipoles have an enhanced effect in the South Pacific because they occur west of the islands, where the Island Rule resets the Sverdrup integration to a constant value; thus the spatial variation of the stream function in the west is determined largely by the local dipoles rather than by the large-scale winds.

[31] Most importantly, when the Sverdrup integration is carried westward from Vanuatu (where the Island Rule stream function value is about zero), the southern negative lobe of the dipole quickly increases the value of the stream function while the northern positive lobe retards it. The result (Figure 4c) is a zigzag of stream function contours, resulting in the eastward Coral Sea Countercurrent (CSCC) flowing toward Vanuatu along $16^{\circ} \mathrm{S}$ [Qiu et al., 2009]. The same zigzag phenomenon is seen west of Fiji to a lesser degree.

[32] The Island Rule solution predicts that the westward flow of the subtropical South Pacific is split twice: first by Fiji into branches north and south of about $17^{\circ} \mathrm{S}$, then the southern branch is split again by New Caledonia [Webb, 2000]. These currents are known as, first, the North Vanuatu Jet (NVJ), which flows through the relatively

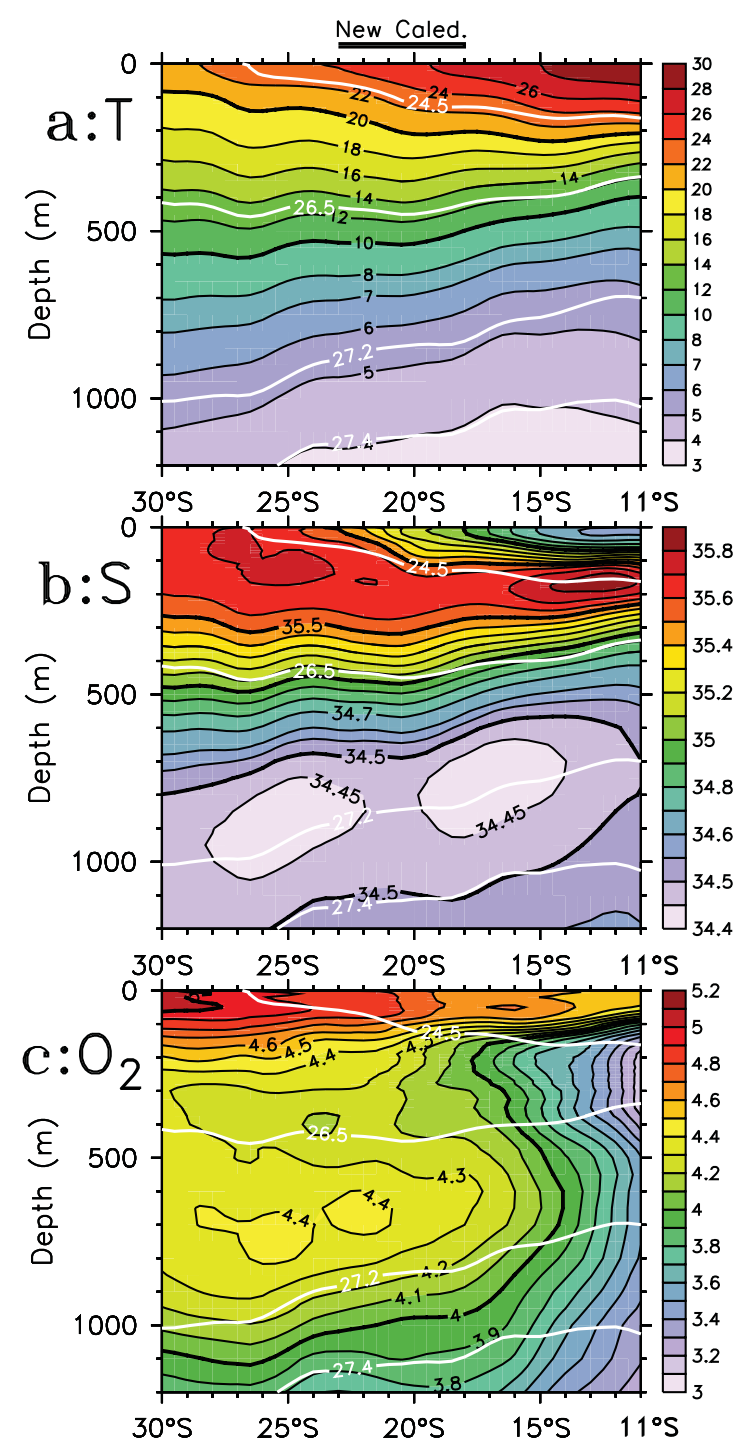

Figure 5. Vertical-meridional sections of (a) temperature $\left({ }^{\circ} \mathrm{C}\right)$, (b) salinity (psu), b) and (c) oxygen concentration $(\mathrm{mL} / \mathrm{L})$ along $162^{\circ} \mathrm{E}$, from the CARS climatology (section 2). White overlaid contours (same on all three plots) show the depths of the isopycnals $24.5,26.5,27.2$, and 27.4. This section is just west of New Caledonia, whose latitude range (including its extensive reef system) is indicated by a solid black bar at the top.

broad opening between Vanuatu and the Solomon Islands; second, the North Caledonian Jet (NCJ), concentrated at $18^{\circ} \mathrm{S}$ just at the tip of the New Caledonian reef; third, the South Caledonian Jet (SCJ) at $24^{\circ} \mathrm{S}$. In the Island Rule representation the NVJ carries about $10 \mathrm{~Sv}$, the NCJ about 12 $\mathrm{Sv}$, and the SCJ about $8 \mathrm{~Sv}$.

[33] With Sverdrup transport approaching Fiji concentrated to the south of the island group (Figure 4c), the meridional averaging that determines the Island Rule stream function value at Fiji is smaller (less negative) than if the transport were uniform, thus most of the incoming transport passes south of Fiji [Stanton et al., 2001]. This means that transport arriving at Vanuatu is even more strongly weighted to its south (the negative wind stress curl 
between Fiji and Vanuatu also contributes to this southward weighting; Figure 4b), and almost all passes south of Vanuatu. As a result, a strong flow approaches New Caledonia near its northern end; the bifurcation along New Caledonia's east coast is shifted to a more negative value and the NCJ/SCJ split is weighted toward the northern jet.

[34] The bifurcation of the western boundary current along the coast of Australia has been the subject of much discussion [Church and Boland, 1983; Church, 1987; Tsuchiya et al., 1989; QL02]. In the present Island Rule solution, the bifurcation streamline is the $-11.3 \mathrm{~Sv}$ contour, which arrives at the coast near $19^{\circ} \mathrm{S}$ (Figure 4c). (Note that this $11.3 \mathrm{~Sv}$ equals the transport of the Indonesian Throughflow in the Island Rule solution.) That contour passes just north of New Caledonia where the coastal stream function value is $-12.0 \mathrm{~Sv}$. Thus, a net change only slightly larger than $0.7 \mathrm{~Sv}$ in the estimated Australia-New Caledonia stream function difference would switch the bifurcation contour south of the island; since this is well within the uncertainty of the calculation the distinction is meaningless and we simply say that the bifurcation is approximately at New Caledonia. (Another recent Island Rule calculation, using QuikSCAT winds, found a similar flow pattern, with stream function value of $-13 \mathrm{~Sv}$ at Australia and $-15 \mathrm{~Sv}$ at New Caledonia) [Couvelard et al., 2008]. According to this vertically averaged representation, westward flow north of New Caledonia largely turns north at the coast of Australia and flows as a western boundary current into the Solomon Sea, while flow south of New Caledonia turns south in the East Australian Current.

[35] As the wind stress curl west of New Caledonia is small (Figure 4b), only weak transport is predicted in the lee of the island. Interior transport is about $1 \mathrm{~Sv}$ northward, and the vertically averaged western boundary current along the Australian coast between $23^{\circ} \mathrm{S}$ and $19^{\circ} \mathrm{S}$ is $2-3 \mathrm{~Sv}$ southward (Figure 4c). The Island Rule-inferred East Australian Current begins at $23^{\circ} \mathrm{S}$ with the $8 \mathrm{~Sv}$ of the SCJ and grows to about $18 \mathrm{~Sv}$ by $30^{\circ} \mathrm{S}$, while the Gulf of Papua Current begins at $19^{\circ} \mathrm{S}$ with the $12 \mathrm{~Sv}$ of the NCJ and grows to $25 \mathrm{~Sv}$ in the Gulf of Papua (Figure 4c). Little net transport flows from the Coral to the Tasman Sea, according to the Island Rule.

[36] Thus from this linear, vertically integrated point of view there is a clear dynamical southern boundary of the Coral Sea in the latitude band west of New Caledonia, where transport arriving from the east in the South Equatorial Current has split irrevocably into poleward and equatorward branches. In the sections below, we will show that the baroclinic structure of these flows in fact produces a current system more complex than this, and in particular that shallow southward and deeper northward transport along the western boundary does occur west of New Caledonia. Nevertheless, the basic picture remains realistic and we will henceforth consider the southern boundary of the Coral Sea to be about $21^{\circ} \mathrm{S}$.

\subsection{Observed Interior Transports Compared to the Island Rule Prediction}

[37] Observed vertically integrated currents (Figure 6) broadly show the same features as the Island Rule (Figure $4 \mathrm{c}$ ), with some clear modifications by topography. The same three westward jets are seen splitting around the

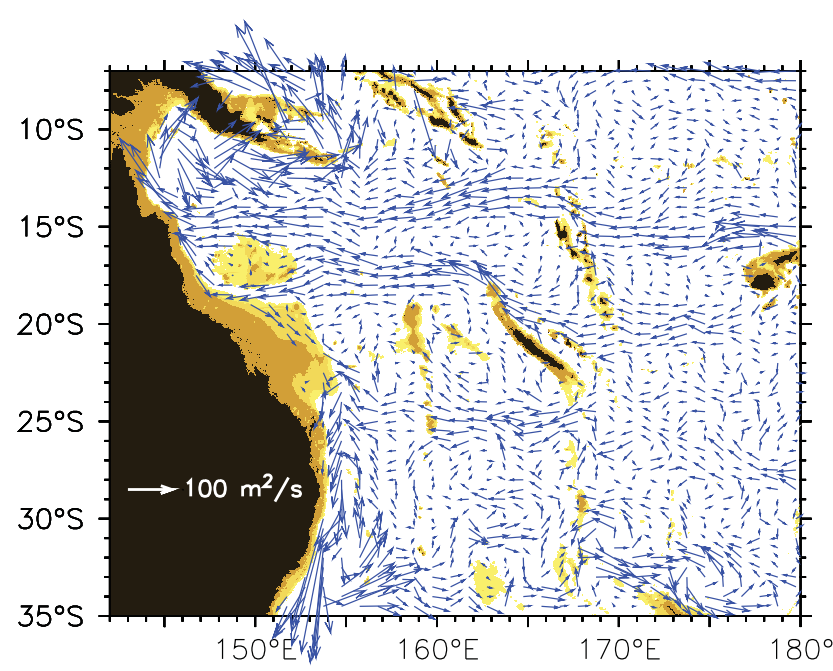

Figure 6. 0-1000 m vertically integrated transport from the referenced geostrophic currents (scale vector inside Australia). Bathymetry as in Figure 1.

islands, as are the weak currents west of New Caledonia and the western boundary current bifurcation near $19^{\circ} \mathrm{S}$. West of Vanuatu, the eastward Coral Sea Countercurrent is observed along $16^{\circ} \mathrm{S}$ to $155^{\circ} \mathrm{E}$, similar to the Island Rule solution (most clearly seen in the stream function of Figure 4c). As a purely linear phenomenon, the Island Rule jets are taken to occur just at the tips of their generating island, and do not broaden as they flow west. Observed currents may be narrow at their origin but broaden with distance; some of this is probably due to nonlinear, mixing and instability processes not encompassed in the Island Rule [Qiu et al., 2009].

[38] Some of the differences between the Island Rule and observed currents can be ascribed to ocean bottom topography, which is absent from Island Rule dynamics; Couvelard et al. [2008] discuss and explicitly model the dynamical effects of Coral Sea topography. Most prominently, the roughly 200 by $400 \mathrm{~km}$ Queensland Plateau centered at $17^{\circ} \mathrm{S}, 150^{\circ} \mathrm{E}$ (Figure 1) has extensive shallows and reefs that effectively block large-scale flow, and is separated from the Great Barrier Reef by a $1000 \mathrm{~m}$ deep, roughly $100 \mathrm{~km}$ wide channel. The observed NCJ, broader than the single-grid point Island Rule jet, encounters the Queensland Plateau and partly splits around it (Figure 6) [see Choukroun et al., 2010].

[39] Observed and Island Rule westward transports entering the Coral Sea can be compared on sections northward and southward from New Caledonia (Figures 7a and $7 \mathrm{~b}$ ). In both cases, the Island Rule jets (North and South Caledonian Jets) have realistic magnitudes (however, note that the jet latitudes in the Island Rule solution depend on the ambiguous choice of island endpoints mentioned in section 3.2). Near New Caledonia, the observed jet cores have approximately the same $1^{\circ}$ latitude width as their Island Rule counterparts. In the north (Figure 7a), the Island Rule correctly places the eastward CSCC at $15^{\circ}-16^{\circ} \mathrm{S}$, but its magnitude is smaller than observed. The most important transport difference is the too weak Island Rule representation of the NVJ at $11^{\circ}-15^{\circ} \mathrm{S}$ (Figure 7a). While observed NVJ transport is about $13 \mathrm{~Sv}$, the Island Rule gives only 9 

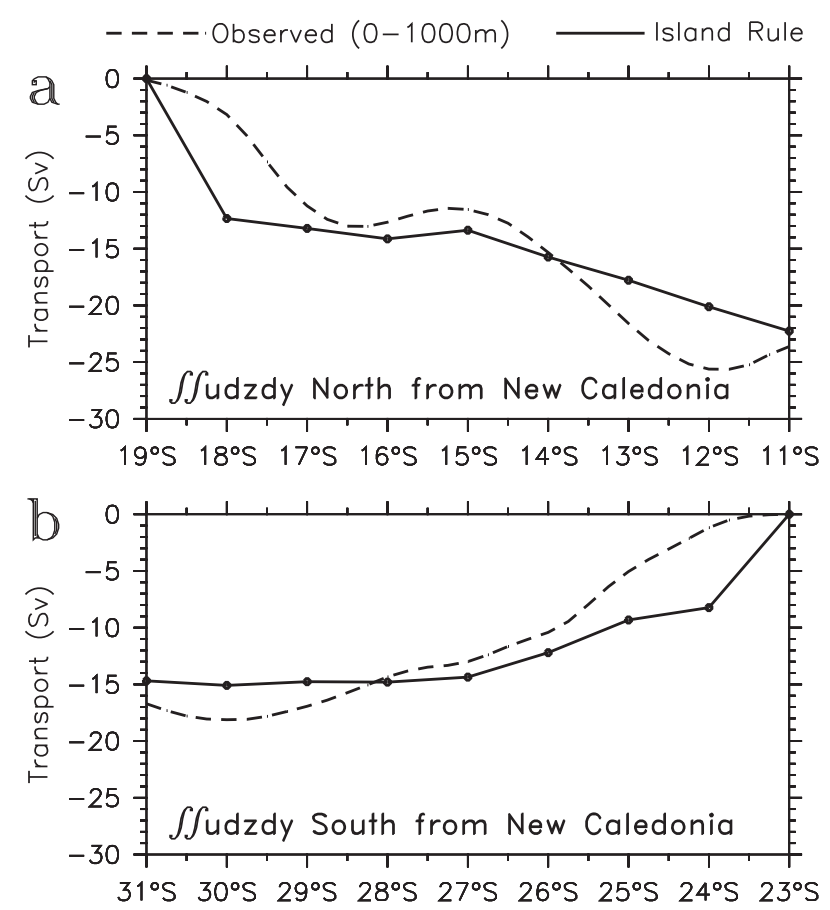

Figure 7. Observed (dashed) and Island Rule-estimated (line) transport (Sv) integrated (a) north (along $162.5^{\circ} \mathrm{E}$ ) and (b) south (along $165.5^{\circ} \mathrm{E}$ ) from New Caledonia. The Island Rule jets occupy the $1^{\circ}$ latitude-wide region immediately adjacent to the island.

Sv; it is not known why this discrepancy occurs. However, both our gridded observed currents and the Island Rule prediction indicate that the NVJ is a broader current than the narrow island jets, consistent with it being an ordinary Sverdrup current largely unaffected by the islands. (We show in section 4.1.2 that the NVJ is also confined much shallower than the deeply extending NCJ and SCJ.) Most of the NVJ does not emanate from the tip of an island, and thus it should not be considered an "Island Rule jet." It is, however, worth noting that some high-resolution OGCMs simulate narrow jets at the northern tip of the Vanuatu Archipelago and through some of its channels (e.g., the $1 / 12^{\circ}$ OCCAM model shown in Figure 6 of Ganachaud et al. [2008]). In our gridded product, there is a poorly resolved suggestion that a small part of the NVJ does originate at the north end of Vanuatu at $14^{\circ} \mathrm{S}$ (Figure $3 \mathrm{a}$ ).

[40] An apparently small difference will turn out to be significant: the turning of much of the NVJ northward into the Solomon Sea near $155^{\circ} \mathrm{E}$ (Figure 6). This feature is absent in the Island Rule solution (most clearly seen in Figure 4c), as Sverdrup currents must have a southward component in this region where the wind stress curl is negative (Figure 4b), and there is no other linear mechanism to produce meridional flow. The northward turn of much of the NVJ directly into the Solomon Sea before encountering the western boundary has been noted previously in observations [Andrews and Clegg, 1989; Gasparin et al., 2012] and models [Melet et al., 2010], and we will show below that this is a significant feature of the Coral-Solomon Sea circulation and its property transports.

[41] The question of flow in the latitude band $24^{\circ} \mathrm{S}-19^{\circ} \mathrm{S}$ west of New Caledonia remains vexing. The Island Rule predicts essentially zero flow in this band, either in the interior or along the western boundary (Figure 4c). Unfortunately, Argo sampling of this region is the weakest in the southwest Pacific (Figure 2). There have been only six float deployments west of New Caledonia $\left(19^{\circ} \mathrm{S}-24^{\circ} \mathrm{S}\right)$; one of these is very recent and two died on the Chesterfield Reefs along $158^{\circ} \mathrm{E}$. Few floats drift into the region: not a single float has passed completely through it from south to north, and only one from north to south (float 5901627, which bounced along the bottom against the Great Barrier Reef in depths of 200-600 m, so its trajectory information is not useful). Several passed partway along the western boundary (in both directions) but died on the reef. Float paths usually bifurcate around New Caledonia either north or south, then head due west to Australia and continue northward or southward along the boundary; that pattern of float drift is consistent with the Island Rule picture of westward jets at each end of the island, with New Caledonia marking a final split of the SEC. However, the sparse sampling means our confidence in the observed circulation pattern west of New Caledonia is low.

[42] From Argo trajectory data, then, one would conclude that flow west of New Caledonia is weak and disorganized (Figure 3a). Geostrophic relative currents from CARS indicate the same thing, with two important (and dynamically linked) exceptions: first, shallow eastward flow is found everywhere in the western South Pacific south of about $15^{\circ} \mathrm{S}$ (Figure 3b) [also see Reid, 1961; Ridgway and Dunn, 2003]. Second, strong upward slopes of isopycnals are observed along the coast of Australia south of $15^{\circ} \mathrm{S}$, in particular above the roughly $400 \mathrm{~m}$ deep Marion Plateau at $19^{\circ}-23^{\circ} \mathrm{S}$ (Figure 1). These imply shallow southward transport along the boundary, and are the source of the southward coastal vectors above topography in Figure 6 . This will be further discussed below in the following sections on the baroclinic circulation.

\section{Observed Baroclinic Circulation in the Interior}

\subsection{Water Masses Entering the Coral Sea}

[43] Water properties are used in this work to trace pathways of flow that has entered the Coral Sea; here we briefly introduce the characteristics of water arriving in the SEC between New Caledonia and the Solomons; for more complete discussions, see Donguy and Henin [1977], Tomczak and Hao [1989], Sokolov and Rintoul [2000], and Maes et al. [2007].

[44] Salinity and oxygen entering the Coral Sea from the east have very different structures, but both exhibit a front near $16^{\circ} \mathrm{S}$ on all density surfaces above about sigma 27 (Figure 8). At thermocline levels, the front is found in the eastward CSCC between the NVJ and NCJ. On the southern side of the front at all depths, higher-oxygen water arriving in the NCJ suggests more recent ventilation than water arriving north of the front in the NVJ. Two distinct high-salinity tongues enter the Coral Sea at different densities. At sigma 24.5, high salinity is on the northern side of the front in the core of the NVJ, while at sigma 26.5, high salinity is on the southern side in the NCJ (Figure 8). At sigma 27.2, where the NCJ is the only significant flow, the sign of the gradient switches again. The front and reversing 


\section{Salinity}
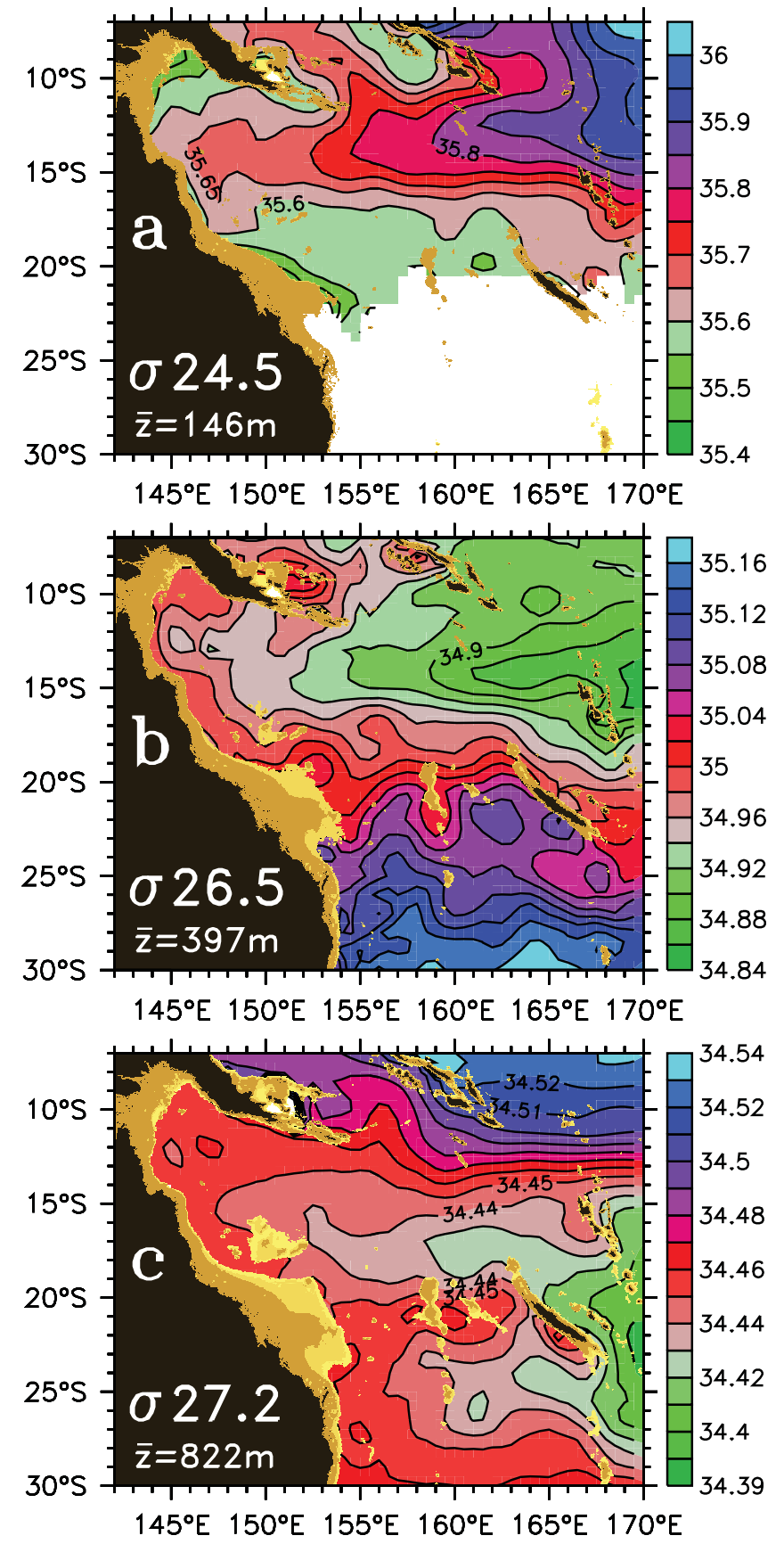

\section{Oxygen}
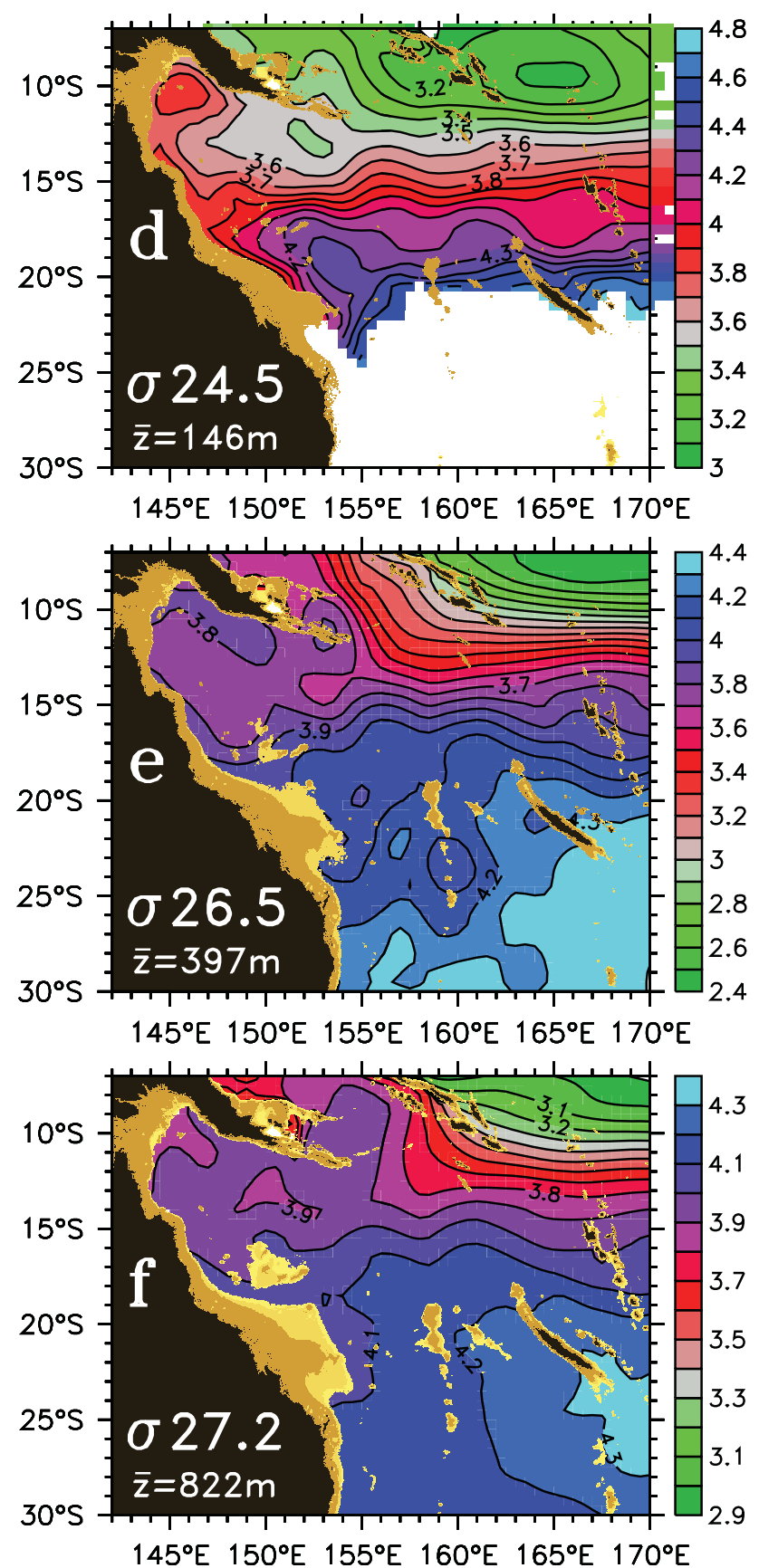

Figure 8. Maps of salinity (psu, left panels) and oxygen concentration $(\mathrm{ml} / \mathrm{L}$, right panels) on the isopycnals (a and d) 24.5, (b and e) 26.5, and (c and f) 27.2, from the CARS climatology (section 2). Each map has its own color scale and contour interval. Regional-mean depths of each isopycnal are indicated at bottom left. Values on the shallow isopycnal 24.5 are only plotted for depths greater than $100 \mathrm{~m}$. Bathymetry as in Figure 1 is shown if the bottom is shallower than the isopycnal.

gradient are most clearly seen in salinity sampled by a glider section from the Solomons to New Caledonia, described by Gourdeau et al. [2008] (Figure 9, right).

[45] These high-salinity tongues have distinct origins. The shallow NVJ carries water that was subducted in the eastern subtropics near $20^{\circ} \mathrm{S}, 120^{\circ} \mathrm{W}$, at the highest surface salinity in the Pacific [Tomczak and Hao, 1989; Delcroix and Henin, 1991; Kessler, 1999; QL02; Grenier et al., 2013]. The deeper high-salinity tongue, in the NCJ south of the front, originated north of New Zealand near $30^{\circ} \mathrm{S}, 180^{\circ}$ [Donguy and Henin, 1977; Tsuchiya, 1981; Roemmich and Cornuelle, 1992; Donguy, 1994; Qu et al., 2008, 2009]. 

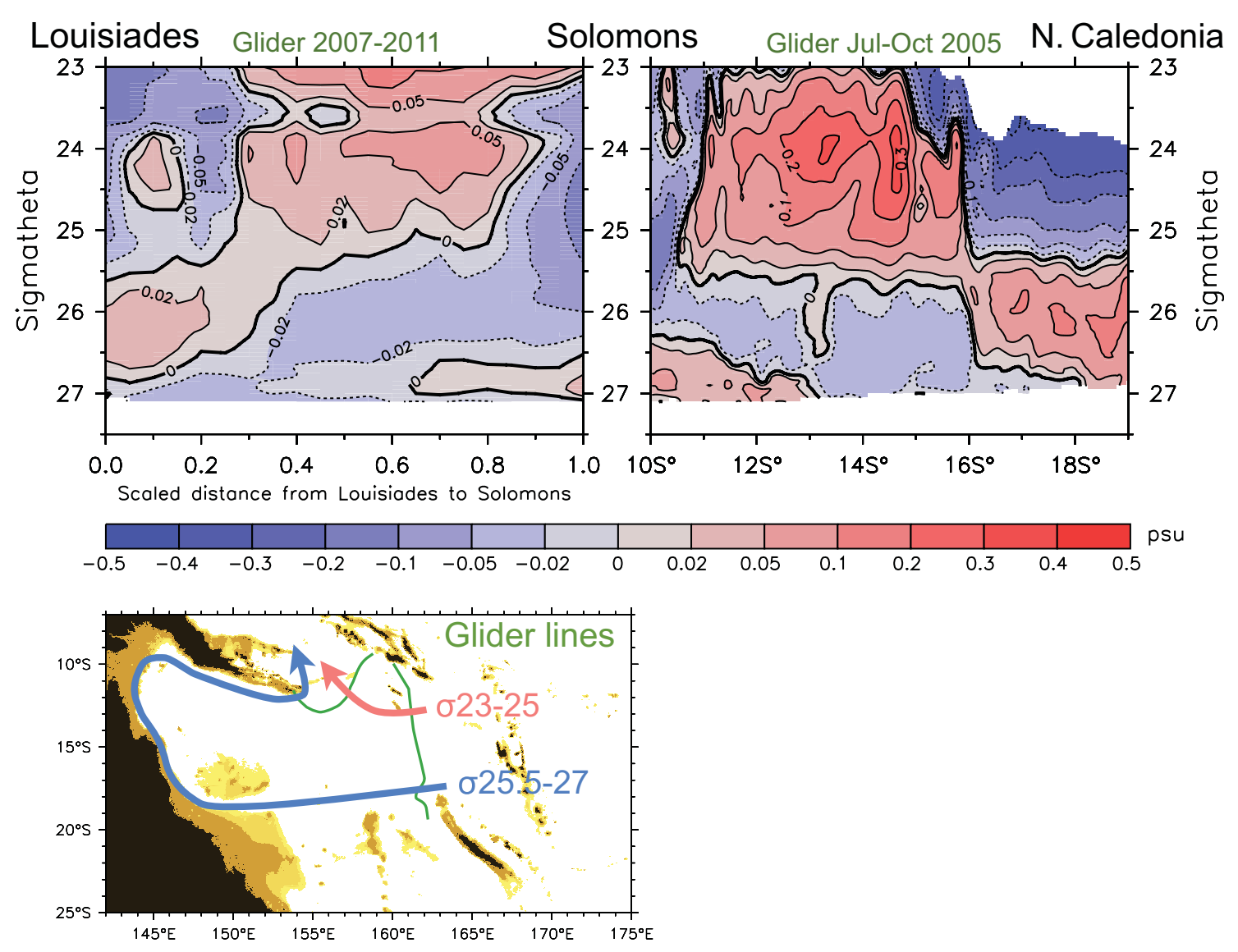

Figure 9. Salinity anomaly sections (psu, common scale at bottom) along glider lines from the southern Solomon Islands to New Caledonia (right), and to the tip of the Louisiade Archipelago (left), oriented so the Solomon Island start point is at the center (bottom keymap shows the glider lines in green). Each upper plot shows the anomaly along isopycnals from the average of the two sections' means. The section on the right is from the single glider mission in mid-2005 [Gourdeau et al., 2008], showing latitude along the section. The section on the left is a composite of many sections over 4 years, binned according to fractional distance from the Louisiades (0) to the Solomons (1) [Davis et al., 2012].

\subsection{Velocities}

[46] The observed circulation reflects the tilted subtropical gyre [Roemmich and Cornuelle, 1990]. The bowl of the gyre is centered near $15^{\circ} \mathrm{S}$ at $20^{\circ} \mathrm{C}$, but is near $20^{\circ} \mathrm{S}$ at $10^{\circ} \mathrm{C}$, and is south of $30^{\circ} \mathrm{S}$ at $5^{\circ} \mathrm{C}$ (Figure 5a); thus the westward gyre flow deepens to the south. Above about 500 $\mathrm{m}$ ( sigma 26.5), isotherms successively break off toward the surface from the general downward slope of the thermocline; south of Vanuatu $\left(15^{\circ} \mathrm{S}\right)$ isotherms above $12^{\circ} \mathrm{C}$ increasingly slope up (Figure 5a). That upward slope indicates eastward geostrophic shear (Figure 3b), implying that the overall westward flow of the gyre is weakened or reversed toward the surface, so westward currents south of about $15^{\circ} \mathrm{S}$ have subsurface maxima [Reid, 1961].

\subsubsection{The North Vanuatu and North Caledonian Jets}

[47] The North Vanuatu Jet, north of $15^{\circ} \mathrm{S}$, is surface intensified and limited to the upper ocean; while it is the strongest of the three jets at sigma 24.5 (Figure 10a), it is much weaker at sigma 26.5, and has disappeared in the directly mapped Argo drift velocities at $1000 \mathrm{~m}$ (Figure
$3 \mathrm{a})$; note that there is almost no slope of sigma 27.4 below the NVJ near $1000 \mathrm{~m}$ (Figure 5a). In other words, the NVJ appears simply as the westward limb of the shallow thermocline gyre, spanning about $400 \mathrm{~km}$ from $15^{\circ} \mathrm{S}$ to $11.5^{\circ} \mathrm{S}$ (Figure 11a), and would be adequately represented by geostrophy relative to $1000 \mathrm{~m}$ (Figure 11b). A slight upward-tothe-south slope of isopycnals above sigma 24.5 at these latitudes, caused as much by salinity as temperature (Figures $5 \mathrm{a}$ and $5 \mathrm{~b}$ ), gives it a maximum speed of about $16 \mathrm{~cm} \mathrm{~s}^{-1}$ at $50-75 \mathrm{~m}$, fairly broad but centered at $13^{\circ} \mathrm{S}$.

[48] By contrast, the North Caledonian Jet (and to a lesser extent the SCJ) is narrower but much thicker vertically (Figure 11a), and both are seen to be prominent features at sigma 27.2 (Figure 10c), where they are identified by the two tongues of low-salinity Antarctic Intermediate Water (AAIW) they carry past the tips of New Caledonia (Figures $5 \mathrm{~b}$ and $8 \mathrm{c}$ ). The isopycnal slopes associated with these two currents remain steep at $1000 \mathrm{~m}$, well below the subtropical thermocline (Figure 5). This large depth extent is consistent with direct observation of the NCJ by lowered acoustic Doppler current profiler (ADCP), which showed 


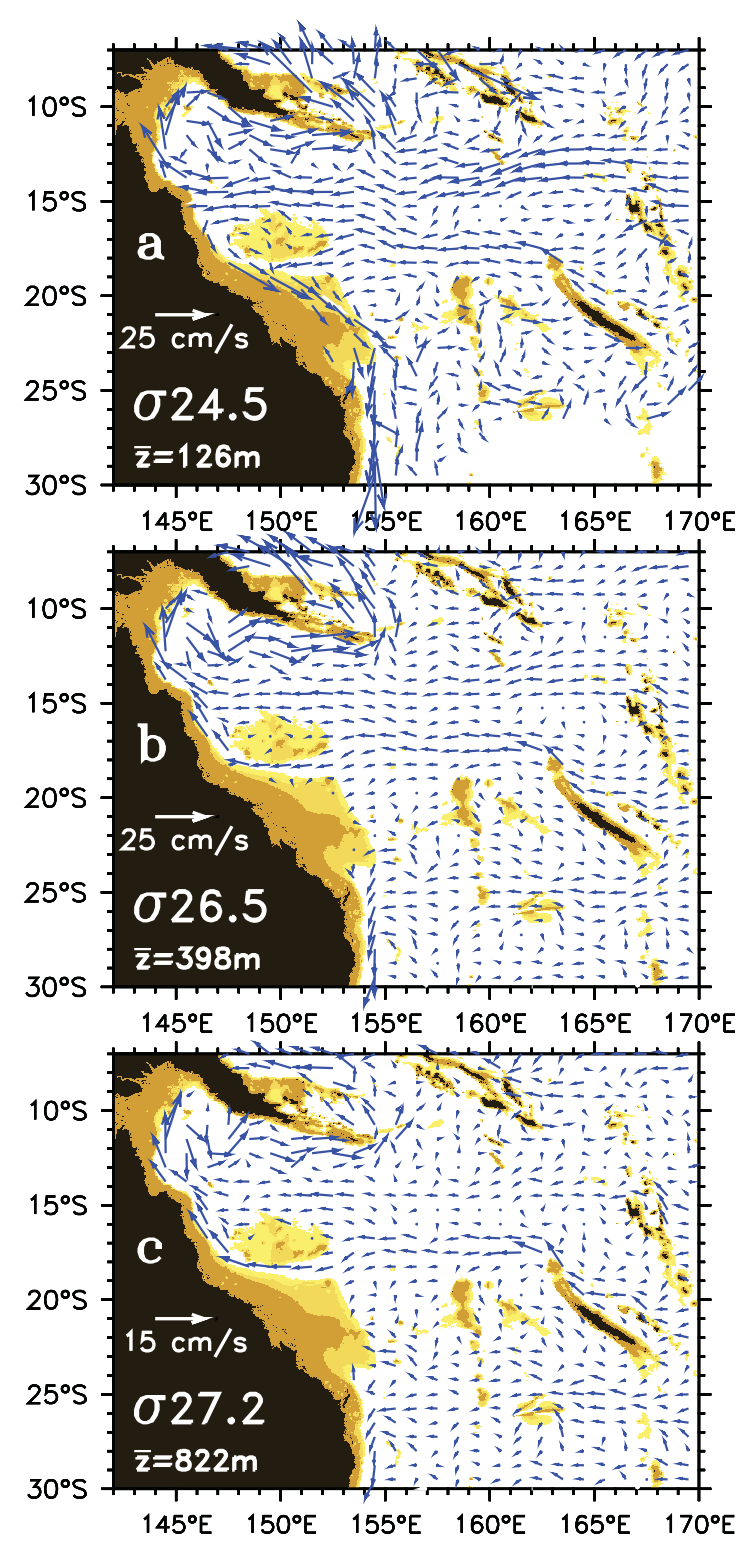

Figure 10. Referenced geostrophic velocity vectors on isopycnal surfaces. (a) On sigma 24.5, with mean depth $126 \mathrm{~m}$ over this region; (b) on sigma 26.5, with mean depth $398 \mathrm{~m}$; (c) on sigma 27.2, with mean depth $822 \mathrm{~m}$. Scale vectors are shown in white over Australia; the upper two plots use the same scale, the bottom plot has an increased scale length. Bathymetry as in Figure 1.

strong westward flow in the NCJ to $1500 \mathrm{~m}$ [Gourdeau et al., 2008; also see Ganachaud et al., 2008; Gasparin et al., 2011].

[49] The NCJ flows across the Coral Sea to at least $154^{\circ} \mathrm{E}$ as a distinct jet, much narrower than the NVJ, with a core only about $100 \mathrm{~km}$ wide, centered at $17.5^{\circ} \mathrm{S}$, and carrying about $13 \mathrm{~Sv}$ above $1000 \mathrm{~m}$ (Figure 7a). This climatological view is confirmed by motion of the individual float tracks [also see Maes et al., 2007]. Twenty-one of the Argo floats studied here passed through the start region of the NCJ at the northern tip of New Caledonia, all with parking depths near $1000 \mathrm{~m}$. Of these, eight are either too recent or died quickly. Of the 13 useful floats, four had irregular motions that took them out of the current. The remaining nine floats $(70 \%)$ drifted from $162^{\circ} \mathrm{E}$ to $154^{\circ} \mathrm{E}$ without crossing either $16^{\circ} \mathrm{S}$ or $20^{\circ} \mathrm{S}$; i.e., they can be seen as being carried by the NCJ at $1000 \mathrm{~m}$. Their mean zonal drift speed over this distance (counting subsurface distances and times only) was $3.1 \mathrm{~cm} \mathrm{~s}^{-1}$, or somewhat less than a year to cross the Coral Sea. Clearly, the NCJ is a coherent feature of the circulation at $1000 \mathrm{~m}$; this is borne out by the mapped Argo trajectories (Figure 3a). On the other hand, isopycnals in the upper NCJ flatten and reverse slope above about 275 $\mathrm{m}$ (Figures 5a and 5b, and note that the near-surface salinity gradient also contributes to this change). This gives an NCJ maximum speed of about $11 \mathrm{~cm} \mathrm{~s}^{-1}$ near $275 \mathrm{~m}$ depth, decreasing to about $7 \mathrm{~cm} \mathrm{~s}^{-1}$ at the surface, and remaining strong and well defined with speeds of $5 \mathrm{~cm} \mathrm{~s}^{-1}$ to $1500 \mathrm{~m}$.

[50] About 2-3 Sv of westward flow joining the NCJ above $300 \mathrm{~m}$ appears to come through the Grand Passage, a gap roughly $35 \mathrm{~km}$ wide and up to $600 \mathrm{~m}$ deep through the northern New Caledonia reef system near $18.75^{\circ} \mathrm{S}$. This is seen as the shallow southern lobe of westward flow in Figure $11 \mathrm{a}$ at $19.5^{\circ} \mathrm{S}-18^{\circ} \mathrm{S}$ (comparable synoptic estimates of transport through the Grand Passage are found in Figure 2 of Gourdeau et al. [2008]) [also see Ganachaud et al., 2008; Gasparin et al., 2011].

\subsubsection{The Eastward Countercurrents}

[51] The eastward-flowing Coral Sea Countercurrent, between the NCJ and NVJ, begins near $157^{\circ} \mathrm{E}$ and increases in magnitude approaching Vanuatu between $15^{\circ}$ and $16^{\circ} \mathrm{S}$ (Figure 10a), consistent with the Island Rule solution (Figure 4c). The CSCC is seen only in the upper layer above about $250 \mathrm{~m}$, intensified toward the surface where its mean speed is near $14 \mathrm{~cm} \mathrm{~s}^{-1}$ (note strong eastward near-

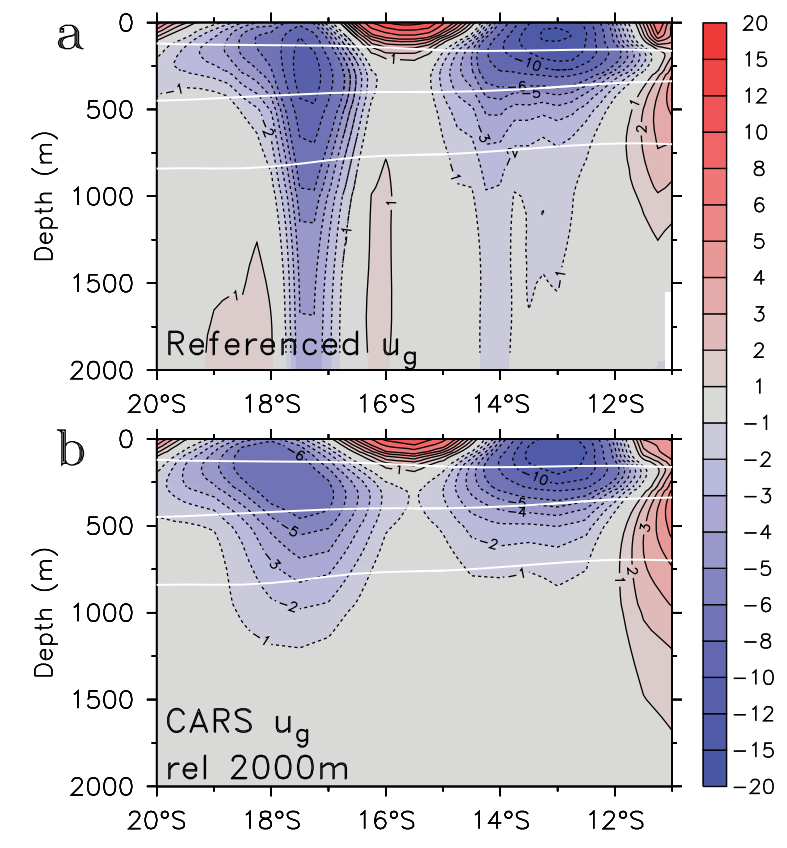

Figure 11. Zonal current across $162^{\circ} \mathrm{E}\left(\mathrm{cm} \mathrm{s}^{-1}\right)$. Positive values (red) indicate eastward flow, negative (blue) westward. (a) Geostrophic currents referenced at $1000 \mathrm{~m}$ by the Argo trajectory velocity. (b) Geostrophic currents from CARS alone, relative to $2000 \mathrm{~m}$. White contours in both plots show the depth of the isopycnals 24.5, 26.5, and 27.2. 
surface shear along $16^{\circ} \mathrm{S}$; Figure $3 \mathrm{~b}$ ). Being shallow and less than $150 \mathrm{~km}$ wide, its transport is only about $1.5 \mathrm{~Sv}$ (Figure 7a). Isopycnal slopes associated with the CSCC are upward to the south only above sigma 26 ; deeper isopycnals at this latitude are flat or slope downward (Figure 5a). Apparently the upwelling effect of the negative curl west of Vanuatu (Figure 4b) is felt only in the upper thermocline. A similar band of upper eastward shear is seen west of Fiji (Figure 3b), apparently due to the similar curl pattern downwind of Fiji (Figure 4b) [see Qiu et al., 2009]. Although not detected in the present mean fields (nor obvious in the individual Argo trajectories), a band of high mesoscale eddy activity is commonly seen in satellite altimeter data along the axis of the CSCC at $16^{\circ} \mathrm{S}$, and was attributed to barotropic shear between the mean eastward CSCC and its westward-flowing neighbors by Qiu et al. [2009].

[52] The observed CSCC is a clear boundary between the NVJ and NCJ east of its origin near $157^{\circ} \mathrm{E}$ (Figure 11a). Approaching the coast of Australia, velocities on sigma 24.5 and 26.5 suggest a partial merging of the two westward currents: the NVJ tends slightly south consistent with the negative wind stress curl over this region (Figures $4 \mathrm{~b}$ and $4 \mathrm{c}$ ), while part of the NCJ appears to turn north, perhaps because of the blocking Queensland Plateau [Choukroun et al., 2010].

[53] Within 50-100 km of Makira Island (the southernmost of the Solomons chain), a thin band of eastward flow is seen north of the NVJ, with about $2 \mathrm{~Sv}$ apparently exiting the Solomon Sea (Figure 6). This counterflow is found in the mapped Argo trajectories (Figure 3a) and also in the geostrophic shear (note the downward slope of the sigma 27.2 and 27.4 isopycnals at the northern end of the $162^{\circ} \mathrm{E}$ section (Figure 5). Both measured and geostrophic depictions suggest a subsurface core; a similar current, closely trapped to the coast and centered near $400 \mathrm{~m}$, was seen in the cruise data of Gasparin et al. [2012].

[54] This picture of the mean currents north of New Caledonia is generally consistent with a detailed absolute velocity section made by an ocean glider crossing from Guadalcanal to New Caledonia roughly along $162^{\circ} \mathrm{E}$ in July to October 2005 [Gourdeau et al., 2008]. In that snapshot, the NVJ was comparably $300 \mathrm{~km}$ broad and shallow, with a maximum speed of more than $20 \mathrm{~cm} \mathrm{~s}^{-1}$ at the surface but virtually absent below about $350 \mathrm{~m}$. Its transport was $21 \mathrm{~Sv}$, about $40 \%$ larger than the mean from the present Argo/CARS data, but at a time of year when this current is known to be seasonally stronger [Kessler and Gourdeau, 2007]. By contrast, the NCJ depicted by the glider was about $100 \mathrm{~km}$ wide, centered at $17^{\circ} \mathrm{S}$, with a 20 $\mathrm{cm} \mathrm{s}{ }^{-1}$ maximum speed and was almost unsheared from the surface to $600 \mathrm{~m}$ as in our mean (Figure 11a); its transport was $12 \mathrm{~Sv}$, the same as found here. The 2005 glider snapshot showed a weak CSCC, mostly indicated by very irregular flow between $14.5^{\circ} \mathrm{S}$ and $16.5^{\circ} \mathrm{S}$, consistent with the eddies known to occur there [Qiu et al., 2009].

\subsubsection{The South Caledonian Jet}

[55] The South Caledonian Jet is the third westward element of the South Pacific subtropical gyre, carrying slightly less transport than the NVJ or NCJ. The mapped SCJ in the present data is less clearly seen than the NCJ. This may be an observational limitation due to the high magnitude of mesoscale eddy variability across this latitude band, as suggested by the sparse in situ observations of the SCJ [Ganachaud et al., 2008], and borne out by satellite altimetry [Qiu et al., 2008].

[56] The SCJ passes over two topographic barriers: the Norfolk Ridge extending south from New Caledonia along $167.5^{\circ} \mathrm{E}$, with sill depths about $1500 \mathrm{~m}$ and many shallower obstructions, and then the Lord Howe Rise along $160^{\circ} \mathrm{E}-$ $162^{\circ} \mathrm{E}$, about $1500 \mathrm{~m}$ deep but with a shallower seamount chain just to its west (Figure 1). It funnels through the deepest gap in the Norfolk Ridge at $25^{\circ} \mathrm{S}$, but appears to break up at the Lord Howe Rise seamount chain (Figure 10, and Ridgway and Dunn [2003]). In contrast to the NCJ, Couvelard et al. [2008] noted a much larger change in the SCJ between a flat-bottom model, where it flowed due west like a typical Island Rule jet, to a model with realistic topography where the current path became convoluted and meandering.

[57] Although the linear Island Rule solution predicts the SCJ to be an island jet emanating directly from the southern tip of New Caledonia (Figure 4c), this character is much less evident in the present observations, where the current appears further offshore than does the NCJ (most clearly seen in the mapped Argo trajectories of Figure 3a). It is not clear how much of the SCJ is fed from the southward branch of the SEC splitting against the east coast of New Caledonia (namely as an Island Rule jet), versus how much derives from other westward offshore flow funneling through the Norfolk Ridge. A further difficulty in characterizing the SCJ in the west is that it approaches the coast of Australia at a latitude where there is a significant western boundary recirculation [Ridgway and Dunn, 2003; Godfrey and Golding, 1981]. Clearly, much about the SCJ remains an unsolved puzzle whose fundamental properties and dynamics are poorly understood.

\subsubsection{Fate of the Entering Currents}

[58] The NVJ, NCJ, and SCJ continue generally westward across the Coral Sea to the coast of Australia. However, the high-salinity tongue of the NVJ branches into the Solomon Sea (Figure 8a). This is consistent with the velocity on sigma 24.5 (Figure 10a) which suggests that part of the NVJ turns north, joining the western boundary current flow entering the Solomon Sea. A similar current structure was seen in glider observations across the mouth of the Solomon Sea [Davis et al., 2012]. This glider sampling also showed that the salinity pattern across the mouth of the Solomon Sea is virtually a mirror of that entering the Coral Sea (Figure 9). We interpret this to indicate substantial transport from the NVJ directly into the central Solomon Sea at isopycnals above sigma 25.5. As noted above (section 3.4), there are no apparent linear mechanisms that would lead to such a northward turn in midbasin. Because of the difficulty in describing the velocity near the tip of the Louisiades from the present data (section 2 above), we are unable to quantify the transport making this northward turn. The picture is further confused because the shallow velocities seem to show a cyclonic eddy in the southeastern Solomon Sea, with southward flow exiting the Sea in the east (Figures 10a and 3b), as was also suggested by the glider analyses of Davis et al. [2012], the Shipboard ADCP (SADCP) compilation of Cravatte et al. [2011] and the modeling study of Melet et al. [2010]. Nevertheless, high- 


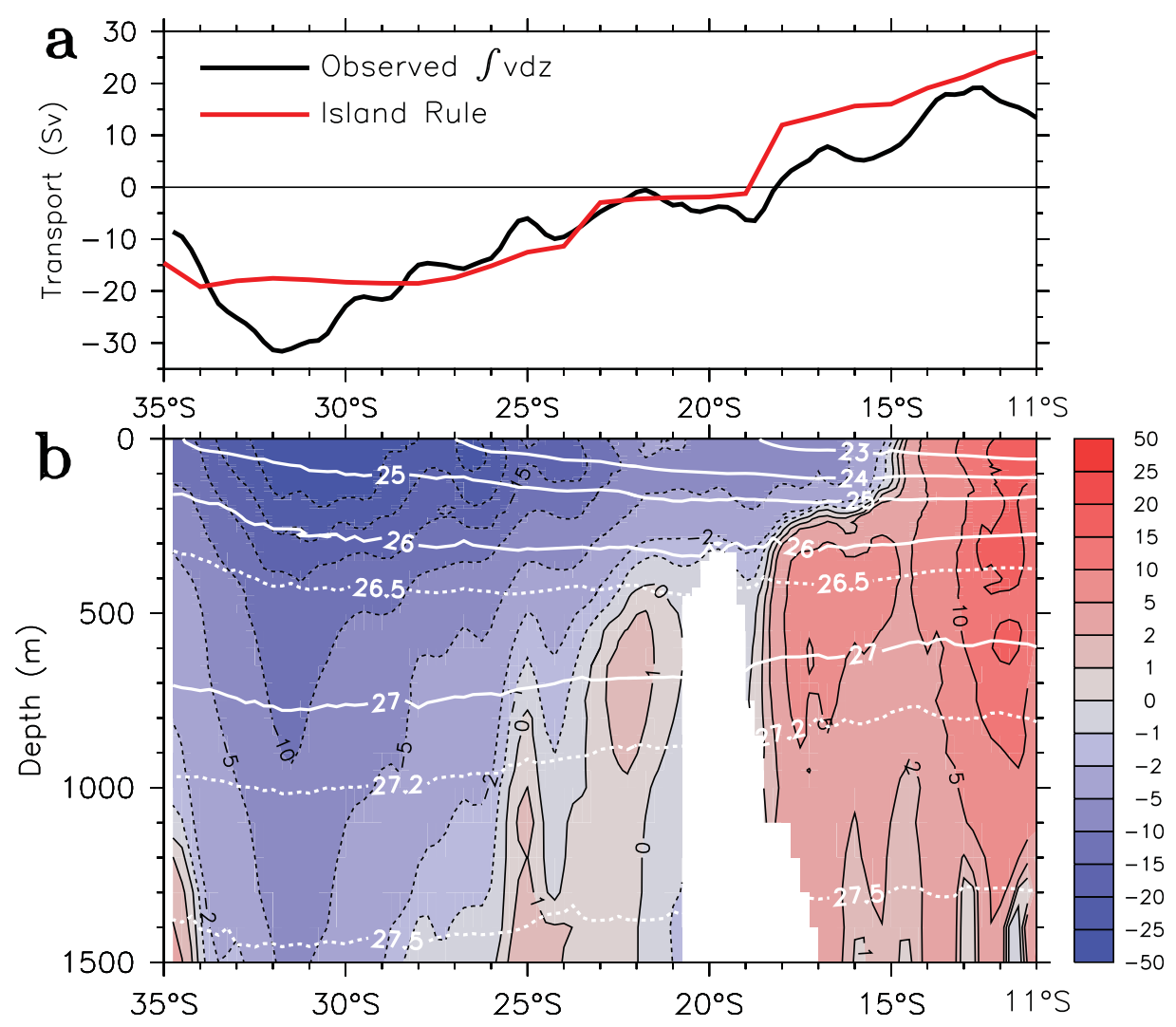

Figure 12. (a) Island Rule (red) and horizontally and 0-1500 m vertically integrated observed (black) western boundary transport ( $\mathrm{Sv}$ ) along the coast of Australia (see section 5.1). (b) Meridional component of observed velocity $\left(\mathrm{cm} \mathrm{s}^{-1}\right)$ averaged across the western boundary layer (see section 5.1). Red indicates northward, blue southward; nonlinear color scale at right. White contours show isopycnals. The blank (white) region near $20^{\circ} \mathrm{S}$ has been omitted because the western boundary jumps eastward too far to be considered continuous.

salinity water from the NVJ quite clearly enters the Solomon Sea east of the boundary current.

\section{Western Boundary Currents}

\subsection{Vertically Integrated Boundary Tran sport}

\subsubsection{Definition of the Western Boundary Layer}

[59] Observed and Island Rule-predicted western boundary transports are compared in Figure 12a. While the Island Rule boundary transports are deduced by conserving mass in the boundary layer; i.e., from the difference between the inshore (Island Rule) and offshore (Sverdrup) stream function values (Figure 4c), both of which are estimated entirely from the wind field, observed boundary currents were calculated from the mapped Argo float drift and climatological geostrophic shear exactly as was done for interior-ocean locations. To estimate "western boundary transport" from the observed currents, we defined the boundary current as the integral of meridional current from the coast to the first zero crossing that was at least $0.5^{\circ}$, but not more than $3^{\circ}$, from the boundary at each depth and latitude. The results were very similar to a simpler definition of $125 \mathrm{~km}$ from the boundary (Figures $13 \mathrm{a}-13 \mathrm{f}$ show that $125 \mathrm{~km}$ is a reasonable choice for boundary current width everywhere except in the complex topography at the Queensland and Marion Plateaus). The channel inshore of the Queensland Plateau is about $1200 \mathrm{~m}$ deep with a sill just below $1100 \mathrm{~m}$; Argo floats drift freely and rapidly through it, with speeds of $5-8 \mathrm{~cm} \mathrm{~s}^{-1}$. However, below $1200 \mathrm{~m}$, the westernmost ocean point is $300 \mathrm{~km}$ further east, offshore of the plateau. It does not seem meaningful or useful to join these two regions, and we have therefore blanked them in Figure 12b. The interesting question of a double western boundary layer-inshore and offshore of the Queensland Plateau-is not yet adequately sampled by the Argo float drift. While there may be a secondary western boundary current east of the Plateau, this topic must await additional data.

\subsubsection{Latitudes West of New Caledonia}

[60] As expected from the streamlines of Figure 4c, there is little vertically integrated boundary transport across the latitude range of $\mathrm{New}$ Caledonia $\left(23^{\circ} \mathrm{S}-19^{\circ} \mathrm{S}\right)$ in either observed or Island Rule representations (Figure 12a), consistent with the idea that the vertical-average bifurcation latitude of incoming flow at the coast of Australia cannot be specified more precisely than that. However, as noted above (section 3.4), sampling in this region is considerably sparser than in the Coral Sea itself; also, much of the (southward) western boundary transport occurs over the shallow Marion Plateau-unsampled by Argo-so our flow estimates there come entirely from CARS geostrophy with an assumed zero reference level at the bottom (Figure 6). 

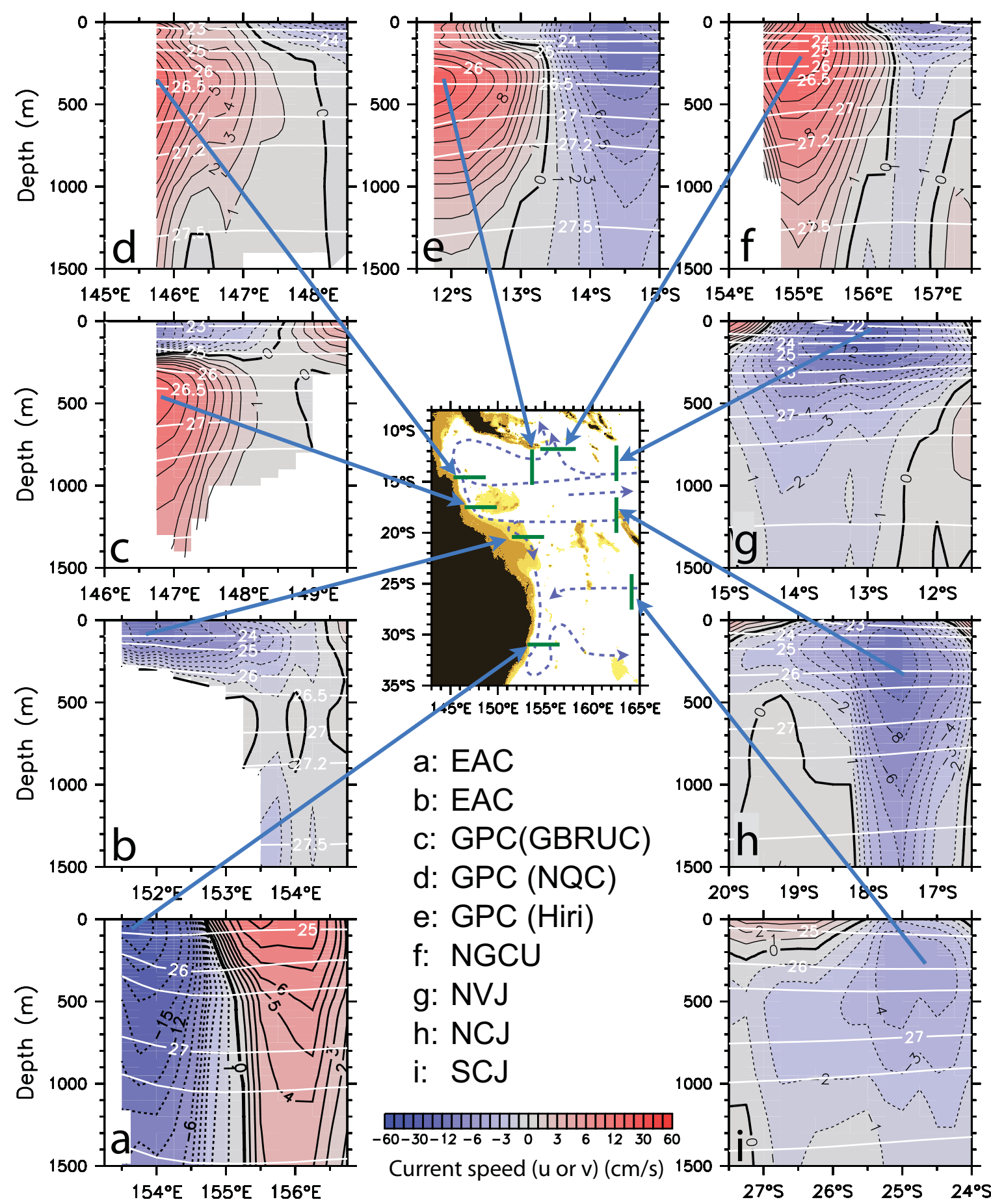

Figure 13. Velocity sections across the key regional currents. Each plot is $3.5^{\circ}$ latitude or longitude wide, and all have the same color scale $\left(\mathrm{cm} \mathrm{s}^{-1}\right.$, bottom). Red colors indicate eastward or northward velocity, blue westward or southward, and the light-blue arrows pointing from the core of each current to green bars on the (middle) reference map show the location of each section. The three plots at bottom right (g-i) show the incoming branches of the SEC (NVJ: g, NCJ: h, SCJ: i). The other sections all have the coast on the left. White overlaid contours show sigma-theta, every $0.5 \mathrm{~kg} \mathrm{~m}^{-3}$. The specific current abbreviations are given below the reference map.

\subsubsection{The EAC South of $23^{\circ} \mathrm{S}$}

[61] South of the bifurcation, both observed and Island Rule-predicted transports show the East Australian Current growing to about $18 \mathrm{~Sv}$ by $28^{\circ} \mathrm{S}$ with the arrival of the southward-turning inflow from the SCJ (Figure 6 and
Ridgway and Dunn [2003]). Further south, the observed boundary transports (estimated from the coast to the zero crossing) become much larger (Figure 12a), but this growth includes only the inshore (southward) half of an increasingly recirculating EAC with substantial northward flow 
offshore [Ridgway and Godfrey, 1994], and therefore does not represent the entire western boundary system (Figures 6 and 13a). If the offshore northward recirculation is included, the total observed transport of the EAC system remains about $18 \mathrm{~Sv}$ to $34^{\circ} \mathrm{S}$.

[62] Much of the EAC turns east at the Tasman Front near $34^{\circ} \mathrm{S}$ (Figure 6 and Ridgway and Dunn [2003], Tilburg et al. [2001]), and observed southward transport drops rapidly (Figure 12). This occurs at $34.5^{\circ} \mathrm{S}$ (north tip of New Zealand) in the Island Rule solution but over the broader band $35^{\circ}-32^{\circ} \mathrm{S}$ in the observed transports. Considering the large contribution of eddies on EAC transport in this latitude range [Godfrey et al., 1980; Ridgway and Dunn, 2003], we do not expect to estimate a useful mean transport from the presently available sampling.

\subsubsection{The Western Boundary Current in the Coral} Sea

[63] North of the bifurcation in the Coral Sea, Island Rule-predicted transport grows rapidly to $12 \mathrm{~Sv}$ as the NCJ is represented arriving at the boundary in a single grid point at $18.5^{\circ} \mathrm{S}$ (Figure 4c), then gradually increases to about 26 $\mathrm{Sv}$ at $11^{\circ} \mathrm{S}$ (Figure 12a). Observed transport grows more slowly, as the NCJ splits around the Queensland Plateau at $16^{\circ} \mathrm{S}-18^{\circ} \mathrm{S}$ (Figure 6) and its transport arrives over a wider latitude range.

[64] Along the Queensland coast north of $13^{\circ} \mathrm{S}$, the observed boundary transport decreases as the current turns offshore and breaks into loops and eddies (Figure 10). The complex currents in the Gulf of Papua have been previously noted [e.g., Scully-Power, 1973; Melet et al., 2010] but their dynamics were not diagnosed, although an inertial overshoot [Bryan, 1963; Veronis, 1966] (Pedlosky [1987], see his sections 5.6 and 5.7) seems likely north of $12^{\circ} \mathrm{S}$, where the coast of Australia is shadowed by the Louisiade Archipelago. We are unable to determine reliably if the loops and eddies are permanent or have preferred locations, but note that many Argo floats spend months or years revolving around the Gulf of Papua in both cyclonic and anticyclonic directions with apparently no consistent pattern. As the climatological geostrophic shear is a rather smooth cyclonic eddy filling the entire Gulf (Figure 3b), but the mapped Argo trajectories show a double loop with smaller scales (Figure 3a), we do not have great confidence that the details of the currents in the interior Gulf shown here (Figure 6) represent a true mean. Since these phenomena are not encompassed by the steady, linear Island Rule dynamics, the discrepancies between the Island Rule and observed transports (Figure 12a) north of $12^{\circ} \mathrm{S}$ are to be expected.

[65] Perhaps more surprisingly, the observed western boundary transport never reaches the magnitude predicted by the Island Rule at any latitude north of the bifurcation (Figure 12a). This apparently reflects the partial loss of NVJ transport directly into the Solomon Sea near $155^{\circ} \mathrm{E}$ before encountering the western boundary (section 4.2.4). Thus some of the westward gyre transport never reaches the western boundary as would be predicted by Sverdrup dynamics; it is not at all apparent why this should occur. Nevertheless, the property tongues extending into the Solomon Sea (high salinity and low oxygen on sigma 24.5 , low salinity and low oxygen on sigma 26.5; Figure 8) confirm its reality, so the explanation for this important piece of the
Coral Sea circulation and property transport remains elusive.

\subsection{Baroclinic Boundary Currents}

\subsubsection{Overview}

[66] QL02 (see their Figure 9) showed that the bifurcation of the South Equatorial Current slopes southward with depth along the Australian coast. Over about $10^{\circ}$ latitude, from $25^{\circ} \mathrm{S}$ to $15^{\circ} \mathrm{S}$, upper flow is southward (the start of the East Australian Current), overlying deeper northward flow that becomes the Gulf of Papua Current and eventually the New Guinea Coastal Undercurrent (Figure 12b).

[67] Cross-shore sections of velocity (Figure 13) show the evolution of the western boundary flows. The NCJ (Figure 13h) supports subsurface maxima of the western boundary currents all around the Coral Sea, with relatively high oxygen (and high salinity on sigma 26.5; Figure $8 \mathrm{~b}$ ) while the shallower NVJ (Figure 13g) brings near-surface flow with low oxygen (and also high salinity; see section 4.1). An alongshore coastal section of oxygen concentration shows the sheared advection along the coast of Australia as these inputs arrive: low-oxygen NVJ and upper NCJ water carried south along the coast above sigma 26, while highoxygen water from the NCJ is carried north along sigma 27 (Figure 15). Compared to the analogous section at $162^{\circ} \mathrm{E}$ (Figure 5c), which is similar to other offshore sections and describes the arriving water properties, the boundary pattern differs by the effect of upper southward and mid-depth northward alongshore advection.

\subsubsection{Southward Boundary Flow: The EAC}

[68] The East Australian Current begins as a shallow $\left(<200 \mathrm{~m}\right.$, above sigma 25.5) southward flow at $15^{\circ} \mathrm{S}$ in the Queensland Passage (Figures 13c, 12b, and 10a) [Church and Boland, 1983, 1987]. It is traced south along the coast across the shallow Marion Plateau (Figure 13b) by lowoxygen water from the North Vanuatu Jet (Figures 14b and 14a); the oxygen sections confirm that the tongue is closely confined to the western boundary and has no possible offshore source of low oxygen south of the NVJ (Figure 8).

[69] The nascent EAC is relatively unchanged until about $23^{\circ} \mathrm{S}$, where it thickens rapidly (Figure $12 \mathrm{~b}$ ) and its oxygen concentration increases at all depths (Figure 15). Both these changes would be consistent with either of two influences: First, the arrival of the high-oxygen South Caledonian Jet at the western boundary (Figures 6 and 5c), and second, the beginning of the EAC offshore recirculation carrying deeply mixed (and thus highly oxygenated) waters and reinjecting them into the EAC beginning near $23^{\circ} \mathrm{S}$ (Figure 6). Further south, the EAC continues to deepen to at least $1500 \mathrm{~m}$ (Figures $12 \mathrm{~b}$ and 13a), which apparently represents the growing influence of the eddying recirculation [Ridgway and Dunn, 2003].

\subsubsection{Northward Boundary Flow: The GPC}

[70] Northward flow along the western boundary (the Gulf of Papua Current; GPC) begins as a weak $(\sim 1.5 \mathrm{~cm}$ $\mathrm{s}^{-1}$ ) current below $800 \mathrm{~m}$ near $25^{\circ} \mathrm{S}$, flowing under the EAC and expanding upward in the tilted bifurcation region (Figure 12b). The tongue of high oxygen along sigma 27 (Figure 15) marks this northward flow. As the North Caledonian Jet arrives at the western boundary near $19^{\circ} \mathrm{S}$, most of its transport below $300 \mathrm{~m}$ ( sigma 26) turns north, into the deep Queensland Passage where GPC strength greatly 


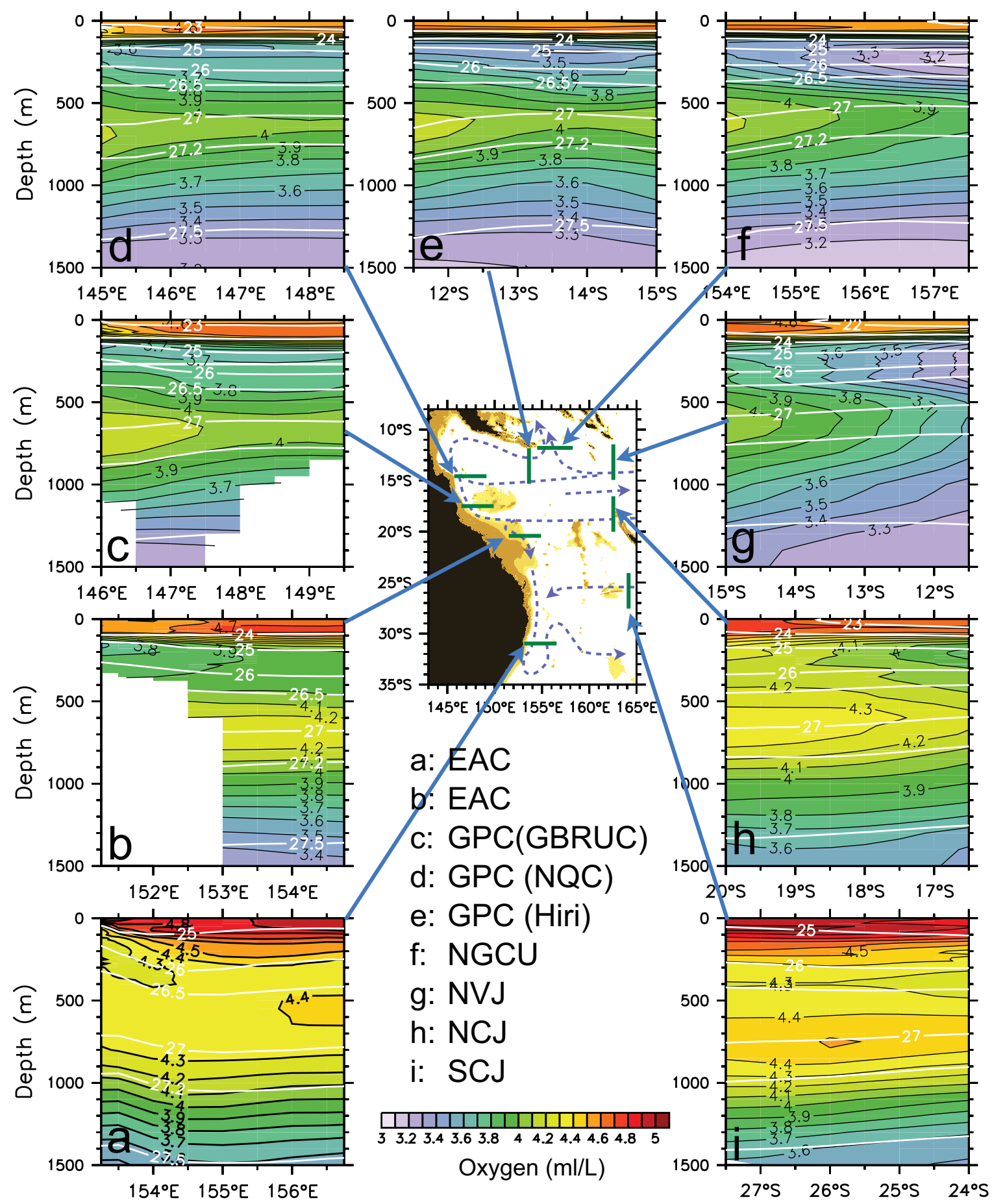

Figure 14. Oxygen concentration sections (mL/L, scale at bottom middle) from the CARS climatology, corresponding to the velocity sections in Figure 13. White overlaid contours show sigma-theta, every $0.5 \mathrm{~kg} \mathrm{~m}^{-3}$.

increases (Figures 12b, 10b, 10c, and 13c); this sheared structure was called the Great Barrier Reef Undercurrent by Church and Boland [1986].

[71] Further north along the Queensland coast, additional flow from the shallow NVJ joins the boundary current, which grows toward the surface (Figure 13d). Around the Gulf of Papua and south of the Louisiades, the eastward boundary current is still about $100 \mathrm{~km}$ wide and largely subsurface (Figure 13e). Further downstream, as the GPC turns the corner into the Solomon Sea (Figure 13f), more shallow NVJ water merges with the inflow (e.g., the highsalinity tongue at sigma 24.5 in Figure 8a; also note the shallow inflow of low-oxygen water arriving east of the Louisiade Chain near $157^{\circ} \mathrm{E}$ in Figure 14f); the equatorward transport grows and thickens, still with a tendency to a subsurface maximum, but extending to the surface. This same character is observed at the northern exits of the Solomon Sea: Vitiaz St. [Lindstrom et al., 1987; Tsuchiya 


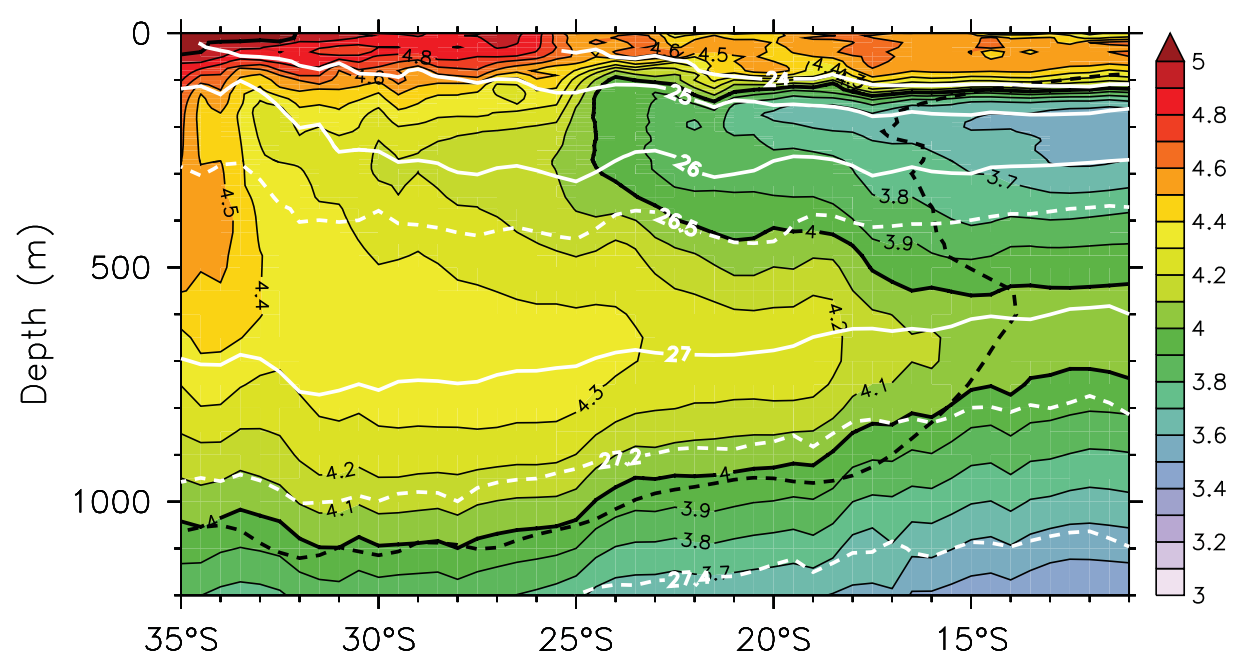

Figure 15. Mean oxygen concentration $(\mathrm{mL} / \mathrm{L})$ along the coast of Australia, from the CARS climatology. White overlaid contours show sigma-theta. Dark solid contour indicates $4.0 \mathrm{~mL} / \mathrm{L}$; the overlaid dark dashed contour shows the corresponding value from a section along $157^{\circ} \mathrm{E}$.

et al., 1989; Lindstrom et al., 1990] and Solomon St. [Butt and Lindstrom, 1994; Cravatte et al., 2011].

\subsubsection{The Bifurcation}

[72] Figure 12b generally confirms the earlier result of QL02, with the bifurcation contour in nearly the same place. The present boundary current velocities are about $50 \%$ larger and they maintain this magnitude much deeper than the QL02 result. This difference is presumably because currents here are referenced to the significant Argo drift velocities at $1000 \mathrm{~m}$ (Figure 3a) while the QL02 currents are relative to a zero at $1200 \mathrm{~m}$. The present results show additionally that the tilted bifurcation is not a smooth slope but is closely related to the arrival of the three westward currents and can be traced by their transports and water properties on density surfaces. Perhaps the bifurcation would be better described not as a tilt but as something closer to two separate layers: above about $250 \mathrm{~m}$ depth (approximately sigma 26) the bifurcation occurs near $15^{\circ} \mathrm{S}$ where the NVJ splits, with its southward part carrying a distinct low-oxygen tongue south along the coast, inside the Queensland Plateau, into the shallow EAC as described above (Figure 15). Below $250 \mathrm{~m}$, the bifurcation occurs near $23^{\circ} \mathrm{S}$ (i.e., south of the NCJ) and the northward subsurface boundary current is dominated by high-oxygen, highsalinity water from the NCJ and SCJ. Additionally, the tilt and sheared boundary current appears to extend deeper and further south than previously realized, with northward flow seen below the EAC, at depths of $1000 \mathrm{~m}$ or more, to at least $25^{\circ} \mathrm{S}$ (Figure 12b). We have less confidence in the shears below $1500 \mathrm{~m}$ so have cut off Figure 12 there, but those suggest that the tilt continues south with depth, to about $29^{\circ} \mathrm{S}$ at $2000 \mathrm{~m}$.

\section{Discussion}

\subsection{Overview}

[73] We have described two principal pathways through the Coral Sea: a broad, shallow (tropical thermocline) route that splits north and south, and a deeper jet-like route that quickly crosses to the coast of Australia and feeds a northward western boundary current that eventually becomes the New Guinea Coastal Undercurrent.

[74] The deeper route enters the Coral Sea in the narrow North Caledonian Jet at the tip of the New Caledonia reef system at $18^{\circ} \mathrm{S}$ (Figure 13h). This Island Rule jet is about $100 \mathrm{~km}$ wide; its maximum is near $275 \mathrm{~m}$ and strong westward flow extends below 1500 m [Gourdeau et al., 2007; Ganachaud et al., 2011]. At all levels the NCJ carries higher oxygen than the NVJ to its north (Figure 8). Below about sigma 25.5 (about $250 \mathrm{~m}$ ), it transmits high-salinity water created northeast of New Zealand [Donguy and Henin, 1977]. The NCJ flows west across the Coral Sea as a distinct jet, so that most of the Argo floats in it go directly and rapidly to the coast of Australia. Although it seems to split around the shallow Queensland Plateau, both branches turn north at the coast and rejoin as a western boundary current that circles the Gulf of Papua clockwise. This grand loop around the Coral Sea is the most prominent feature in the mapped Argo trajectories at $1000 \mathrm{~m}$ (Figure 3a). This subthermocline boundary flow is traced by high oxygen (AAIW at sigma 27.1, centered at about $650 \mathrm{~m}$ ) and high salinity (in the layer sigma 26-27) tightly trapped to the coast, that eventually reaches the Solomon Sea to begin the New Guinea Coastal Undercurrent [Qu and Lindstrom, 2004].

[75] The shallow route enters the Coral Sea in the North Vanuatu Jet at $11^{\circ} \mathrm{S}-14^{\circ} \mathrm{S}$, surface intensified and occurring mostly above sigma $26(300 \mathrm{~m})$. It is not an Island Rule jet, but is simply an unobstructed part of the South Equatorial Current, carrying high-salinity, low-oxygen water that was created in the eastern subtropics [Kessler, 1999; Qu et al., 2008]. About half of this inflow breaks off in the central Coral Sea, turning north into the Solomon Sea, where it is the source of the high-salinity water found on thermocline isopycnals. The other half continues to the coast of Australia where it splits north and south. The northward part joins the subsurface flow from the NCJ, extending the boundary current toward the surface (Figure 13, compare plots $\mathrm{c}$ and d). A smaller part turns south, to begin the East 
Australian Current. This flow is traced by a tongue of low oxygen in the layer sigma 25-26 along the boundary as far south as $30^{\circ} \mathrm{S}$ (Figure 15 ).

[76] We have taken the viewpoint of a climatological mean circulation, while knowing that the Coral Sea, like much of the rest of the ocean, is vigorously turbulent and variable at all time scales. In particular, we note observations of energetic eddies along the front at $16^{\circ} \mathrm{S}$ [Qiu et al., 2009], and in the Gulf of Papua [Scully-Power, 1973]. And although we see a mean South Caledonian Jet in the referenced geostrophic currents reported here, synoptic observation of this current (or model snapshots), do not show this current except episodically [Ganachaud et al., 2008]. These regions of turbulent flow can be expected to accomplish significant mixing. Nevertheless, the observations reported here and elsewhere show that such mixing is not overwhelming (e.g., the demonstration by Tsuchiya [1981] that water properties formed near New Zealand remain coherent enough to be readily identifiable after passing through the North Caledonian Jet, the Gulf of Papua Current, the New Guinea Coastal Undercurrent, and the near-equatorial "Tsuchiya jets," to the far eastern Pacific). Clearly, the role of eddy mixing in the Coral Sea remains to be fully explicated.

\subsection{Mass Transport Balance Entering and Exiting the Coral Sea}

\subsubsection{Uncertainties of the Transport Estimation}

[77] We have refrained from specifying numerical values for total transport leaving the Coral Sea to the north and south, despite the desirability of doing so. One of the main findings here is that much of the transport occurs in narrow jets close to coastlines and reefs, through constricted channels, or over shallow topography, that are often not well sampled. In our judgment, the coast-to-coast transport values depend too sensitively on these endpoints; despite the ability to reference with the Argo trajectory velocities, experiment showed that apparently small changes in methodology produced quantitatively different estimates of transport.

[78] The inability to specify the mean mass transports exiting the Coral Sea is an unfortunate failure of this work; indeed, one of our principal motivations for using the Argo trajectory velocities as a reference was to do exactly that. Credible estimates of the exiting transport distribution would resolve the essential question of the destination of South Equatorial Current transport as it bifurcates at the coast of Australia, which has occupied much previous work beginning with Wyrtki [1960] and continuing to the present [e.g., Gasparin et al., 2012]; see the section 1. They would also anchor studies of annual, interannual and lowerfrequency variability that are highly relevant for the climate of the western and equatorial Pacific. However, we do not have high confidence in the numerical transport values of the meridional distribution of exiting flow, and therefore forwent such specification in the description above.

[79] Nevertheless, it is worth showing the transport balance resulting from the velocity field deduced here, to demonstrate its uncertainty and for comparison with future observations that hopefully will produce more confidence. Figure 16 shows the estimated transport in density layers across the sides of a box enclosing the central Coral Sea. Strong incoming flow is found in all layers, totalling 27.4 Sv above sigma 27.5. Transport exiting north into the Solo-

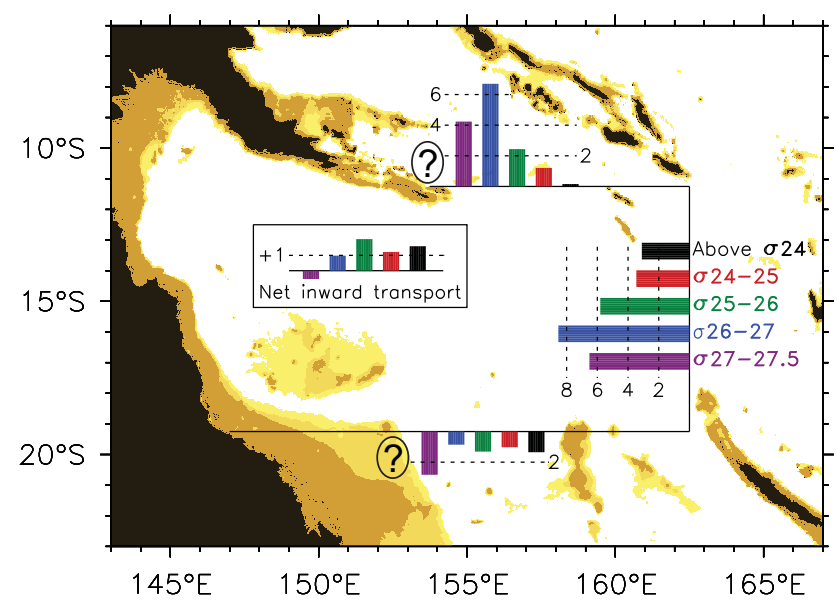

Figure 16. Approximate (and unbalanced) transport budgets (Sv) in density layers across the sides of a box enclosing the Coral Sea. Black shading is land, and brown shading indicates depths at 100,500 , and $1000 \mathrm{~m}$. The colored transport bars are oriented inward or outward according to the direction of transport, with the same color scheme for each side (labeled for the $162.5^{\circ}$ section) and dashed lines indicate the transport scale. The central outlined box shows the net inward transport (imbalance) in each layer. Bathymetry as in Figure 1. The two question marks near the western ends of the box indicate locations of particular uncertainty (see section 6.2).

mon Sea above this isopycnal is about $14.7 \mathrm{~Sv}$, and is dominated by flow between sigma 26 and 27 (roughly 300-600 m depth, consistent with other observations of a subsurface maximum in the New Guinea Coastal Undercurrent) [Gasparin et al., 2012; Davis et al., 2012]. Flow exiting to the south totals $7.3 \mathrm{~Sv}$ and is weak in all layers. The net inward transport of $5.3 \mathrm{~Sv}$ is the imbalance of this estimate; thus about $20 \%$ of the incoming flow cannot be accounted for in the exit sections. We believe that at least most of this unmeasured transport in fact leaves to the north, principally in the New Guinea Coastal Undercurrent. It is also possible that some of the $7.3 \mathrm{~Sv}$ of the southward flow implied by this analysis in fact leaves to the north as well.

\subsubsection{Transport Entering the Coral Sea}

[80] On the other hand, relatively good sampling (Figure 2) gives more confidence in our estimate of the mean absolute geostrophic transport entering the Coral Sea between New Caledonia and the Solomon Islands, which we find to be $24 \mathrm{~Sv}$ above $1000 \mathrm{~m}$ (Figure 7a), $26 \mathrm{~Sv}$ above $1500 \mathrm{~m}$, and $27 \mathrm{~Sv}$ above $2000 \mathrm{~m}$. These values include about $2 \mathrm{~Sv}$ of shallow westward transport through the Grand Passage (section 4.2), and a slightly larger eastward transport at the northern end of the section next to the Solomon Island chain (Figure 7a). Note that these calculations of coast-tocoast transport are similar to, but not the same as, transports through the east side of the box shown in Figure 16 and cited above.

[81] These estimates were tested by comparing results from integrating along different pathways between New Caledonia and the Solomon Islands, examining both the part due to relative geostrophy from CARS and that from our mapped $1000 \mathrm{~m}$ velocities based on Argo trajectories. 
As the NCJ is well sampled by many Argo trajectories close to the tip of New Caledonia where the $1000 \mathrm{~m}$ flow is less variable, most of the ambiguity causing differences between pathways occurs at the northern end of the section where fewer Argo floats have passed near the southernmost Solomon Island (Makira). Kessler and Cravatte [2013] compiled all historical estimates of geostrophic transport (relative to various levels of no motion) between New Caledonia and the Solomon Islands and found values varying between 25 and $30 \mathrm{~Sv}$, relative to $2000 \mathrm{~m}$ (their Table 1), similar to those found here. They also found ENSO variability of up to $\pm 10 \mathrm{~Sv}$, which could affect the estimate of mean transport reported here. Overall, the uncertainty of estimated mean transport entering the Coral Sea is at least $\pm 3 \mathrm{~Sv}$, or about $10 \%$ of the total.

[82] If only geostrophic relative transports from CARS were available (without the ability to reference by Argo trajectory velocity), the zonal current section would be as shown in Figure 11b, with a similar NVJ but much broader and shallower NCJ. Net transport entering the Coral Sea above $1000 \mathrm{~m}$ depth would be estimated to be $20 \mathrm{~Sv}$ relative to $2000 \mathrm{~m}$, and $18 \mathrm{~Sv}$ relative to $1000 \mathrm{~m}$, about $14 \%$ and $24 \%$, respectively, smaller than the referenced value. The transport imbalance in Figure 16 does not change very much in these cases, however, because flow out the northern side of the box decreases by about the same amount.

\subsubsection{Transport Exiting Southward}

[83] The situation is not as good for the flows exiting the Coral Sea north and south. A particular problem in estimating the southward transport is that much of the boundary current appears to occur over the roughly $400 \mathrm{~m}$ deep Marion Plateau at $19^{\circ}-22^{\circ} \mathrm{S}$, where water properties and isopycnal slopes indicate southward flow but there is no Argo sampling, and we chose to reference geostrophy at the bottom (Figure 13b). The resulting estimated boundary transport values have alongshore fluctuations of 3-5 Sv in this latitude range (Figure 12a) that could as easily be due to the choice of bottom referencing as to real flow variations. These wiggles imply an effective minimum uncertainty on how well we can estimate transport between New Caledonia and Australia (namely the flow from the Coral to the Tasman Sea). Meridional flow outside the coastal boundary layer in this latitude band appears weak, from both Argo trajectories and from CARS geostrophy (Figure 3 and see section 3.4 above). However, even if the uncertainty is larger than this, there is little evidence of significant transport that has entered the Coral Sea between New Caledonia and the Solomons turning south into the Tasman Sea, as some have argued [Wyrtki, 1962b; Andrews and Clegg, 1989; Sokolov and Rintoul, 2000].

[84] Salinity and oxygen on isopycnals show a strong contrast between Coral Sea water and that south of $18^{\circ} \mathrm{S}$, at all levels (Figure 8). Except for the finger of low-oxygen water from the NVJ that penetrates south along the western boundary near sigma 25 (about $250 \mathrm{~m}$ depth; Figures 15 and $14 \mathrm{a}, 14 \mathrm{~b}$ ), water properties indicate only weak southward boundary transport exiting the Coral Sea.

[85] We estimate that net transport between New Caledonia and Australia is probably southward but is unlikely to be larger than about $6-8 \mathrm{~Sv}$. This is still substantially more southward transport than the Island Rule estimate of
$0.7 \mathrm{~Sv}$. But in any case, the main growth of EAC transport (and its increasing thickness) occur with the arrival of the South Caledonian Jet near $23^{\circ} \mathrm{S}$, not from the Coral Sea (Figure 12b), and most of the NCJ appears to turn north at the coast of Australia.

[86] This inference is consistent with other recent estimates from climatological data and repeat sampling. Ridgway and Dunn [2003] used an earlier version of the CARS climatology and showed a similar intensification of the EAC with the arrival of SCJ inflow (their Figure 10 and section 6.2). Roemmich et al. [2005] studied highresolution repeat expendable bathythermograph (XBT) sections made during 1991-2002 on the PX30 line. This line sampled from just south of New Caledonia to Brisbane, Australia $\left(27^{\circ} \mathrm{S}\right)$; that is, diagonally across the SCJ and then across the EAC south of the SCJ's arrival at the coast of Australia. Roemmich et al. found about $7 \mathrm{~Sv}$ total southward geostrophic transport across this line (relative to 2000 $\mathrm{m}$ depth) above the $12^{\circ} \mathrm{C}$ isotherm (about $450 \mathrm{~m}$ ). The PX30 data showed northwestward cross-track flow near New Caledonia (apparently the SCJ), then a northward recirculation just east of a strong (14 Sv), narrow EAC (their Figure 1). An analogous section from the present data is similar, though our EAC is weaker: about $10 \mathrm{~Sv}$ cross track above $12^{\circ} \mathrm{C}$. Overall, then, modern data compilations do not suggest a large southward transport from the Coral to the Tasman Sea as had been proposed by some early studies or analyses of individual cruises.

\subsubsection{Transport Exiting Northward}

[87] A different problem occurs at the northern boundary of the Coral Sea, where one would like to know the transport entering the Solomon Sea that subsequently feeds the equatorial circulation [Fine et al., 1994; Tsuchiya et al., 1989; Melet et al., 2010; Grenier et al., 2011]. In this case the difficulty is that the Louisiade Archipelago that forms the western boundary is narrow (50-60 km across), and the CARS climatology appears to interpolate properties across it, especially at the eastern tip (in fact CARS includes "ocean" values across much of the eastern Louisiades). As mentioned in section 2, recent glider and shipboard observations make clear that the northward boundary current is very strong close to the tip of the Louisiades [Davis et al., 2012; Gasparin et al., 2012], and we consider the result from the present data (about $15 \mathrm{~Sv}$ exiting the Coral Sea to the north) an underestimate.

[88] We note that transports estimated from individual ship or glider sections can be badly aliased by eddies and internal wave noise, and that ENSO variability amplitude is at least 25\% of the mean transport [Davis et al., 2012; Kessler and Cravatte, 2013]. We conclude that neither individual sections nor presently available climatologies produce accurate representations of the mean transport exiting the Coral Sea either north or south. Our focus here has therefore been on the characteristics and mechanisms that produce and control the Coral Sea circulation.

\subsection{Dynamics of the Tilted Western Boundary Current Bifurcation}

\subsubsection{Overview : Nonlocal Forcing}

[89] The meridional structure of the Coral Sea western boundary current can be understood as governed by two basin-scale influences: the zonal currents bringing and 
removing mass from the western boundary layer, and the net meridional transport through the South Pacific required by the Indonesian Throughflow (ITF). These two factors determine which way a particular element of zonal inflow or outflow to the boundary region will turn at the coast, and thus determine the shape of the bifurcation. Neither of these factors can be understood considering the Coral Sea region in isolation.

[90] The shallow southward western boundary flow that begins the East Australian Current in the tilted bifurcation region (Figure 12b) demonstrates the significance of nonlocal forcing. This current is geostrophically associated with isopycnals sloping up to the coast; for example, the sigma 24.5 isopycnal is at least $20-30 \mathrm{~m}$ shallower at the coast than 100 $\mathrm{km}$ offshore, everywhere from $30^{\circ} \mathrm{S}$ to $15^{\circ} \mathrm{S}$. This upward-tothe-coast slope cannot be the result of the local winds, which are strongly alongshore to the northwest - and thus Ekman downwelling - all year along this coast north of $28^{\circ} \mathrm{S}$ (Figure $4 a)$. The shallow southward boundary current and resulting southward turn of the NVJ through the Queensland Passage therefore must be remotely forced. Since the deeper northward boundary current also cannot be locally forced, this sheared system, uniquely among the subtropical gyres of the world ocean spanning at least $8^{\circ}$ latitude, represents a distinct characteristic of the South Pacific as a whole.

\subsubsection{Net Meridional Transport Through the South Pacific}

[91] From a steady, linear (Island Rule) point of view, transport between Australia and South America must be the same at all latitudes from Tasmania to the equator, which therefore gives the transport of the ITF (ignoring flow through Bering Strait). Vertically integrated western boundary transport is thus the difference between the interior Sverdrup transport at each latitude and the Island Ruleestimated ITF transport (11.3 Sv for the winds studied here; see section 3 ). With the zonally integrated zero wind stress curl line near $18^{\circ} \mathrm{S}$ (Figure $4 \mathrm{~b}$ shows the western part), one can infer that the boundary current will transport about 11.3 Sv northward at that latitude (Figure 12a). Since the Sverdrup transport is southward north of that line, and northward to its south (Figure 4), the integrated western boundary currents will tend in the opposite sense.

\subsubsection{Zonal Inflows and Outflows to the Western Boundary Layer}

[92] The tilted South Pacific subtropical gyre produces upper eastward shear overlying deeper westward currents; while we have seen that flow at thermocline level and below is almost entirely westward (Figure 10), surface flow is largely eastward south of $15^{\circ} \mathrm{S}$ (Figure $3 \mathrm{~b}$ shows the upper shear) [see Donguy and Henin, 1977; Ridgway and Dunn, 2000]. This shallow eastward interior transportremoving mass from the western boundary layer-must be balanced by shallow alongshore convergence, while the deeper westward inflow is balanced by alongshore divergence in the boundary layer. These produce the alongshore and vertical shear in the boundary layer, which can be referenced by the known total boundary transport.

[93] An appropriate place to start the integration is the Tasman Front at $34^{\circ} \mathrm{S}$, where the boundary current is southward (because the wind stress curl is most negative there) and deep mixing produced by the eddying EAC recirculation [e.g., Cronin, 1996] means that the current is southward at all depths (Figure 12b). At successive latitudes to the north, the shallow convergence forced by the eastward interior flows means that the upper boundary current becomes more southward $(\mathrm{d} V / \mathrm{d} y<0)$, while the deep divergence due to westward inflow means that the lower boundary current becomes more northward $(\mathrm{d} V / \mathrm{d} y>0)$. These tendencies must stay in balance with the weakening of the total boundary transport as the cross-basin wind stress curl decreases to the north (Figure 4b). At some latitude south of the zero wind stress curl line, the interior transport will equal 11.3 Sv (northward), and the vertically integrated boundary transport will therefore be zero. This implies that the boundary current at that latitude will have upper southward and deeper northward flow, as seen in the observed boundary current profile (Figure 12b). Further north, in the Coral Sea itself, the interior currents are strongly westward at all depths (Figure 10) and thus imply convergence in the western boundary layer. The resulting boundary current shear is thus northward, strengthening the deep northward alongshore current, and quickly weakening and reversing the upper southward current to produce the thick GPC that feeds the NGCU.

[94] In this light, the southward near-surface EAC north of about $28^{\circ} \mathrm{S}$ and extending into the Coral Sea is seen as a response to shallow eastward (offshore) flow and consequent alongshore convergence in the south. Similarly, the deep origin of the GPC near $25^{\circ} \mathrm{S}$ is the result of subthermocline westward transport in the central subtropical gyre. The tilted bifurcation is the result of this interplay between the total boundary transport (determined by the meridionalaverage wind stress curl, see section 3.1) and the pattern of interior zonal currents adding and removing mass from the boundary layer. The presence of New Caledonia near the zero boundary current region complicates the picture locally, but does not change the fundamentals.

\subsubsection{Importance of the ITF for the Bifurcation \\ Latitude and Tilt}

[95] We can now ask what would happen to the tilt of the bifurcation if the ITF were closed. If winds over the Pacific remained the same, the interior wind-driven (Sverdrup) flow would be unaltered; the only change could be in the western boundary current. As in the North Pacific, with zero total meridional transport, the time-mean boundary current would exactly balance the interior meridional Sverdrup transport at each latitude (again ignoring Bering Strait). With the ITF closed, the Island Rule western boundary transport would be uniformly more negative along the entire coast of Australia: the red curve in Figure 12a would be shifted downward $11.3 \mathrm{~Sv}$. The bifurcation streamline in the Coral Sea would be the zero Sverdrup transport contour (thus unquestionably north of New Caledonia; Figure 4c), and the NCJ would turn south at the coast of Australia, increasing the transport of the EAC by 11.3 Sv and decreasing the equatorward western boundary transport toward the Solomon Sea by the same amount. If this extra 11.3 Sv were uniformly distributed over the upper $1500 \mathrm{~m}$ of the boundary current (equivalent to subtracting $5.4 \mathrm{~cm} \mathrm{~s}^{-1}$ from the current shown in Figure 12b), the resulting western boundary flow would be southward at all depths from about $18^{\circ} \mathrm{S}$, while shifting the surface bifurcation less than $1^{\circ}$ north. The tilt of the bifurcation would 
then span only about $3^{\circ}$ latitude and be comparable to the small tilt seen in the North Pacific [Qu and Lukas, 2003]. Even if the distribution of this 11.3 Sv was weighted more heavily toward the surface, the resulting bifurcation latitude range would be greatly lessened. McCreary et al. [2007] did the experiment of closing the ITF in a hierarchy of models and found that the bifurcation tilt indeed nearly disappeared.

\subsubsection{Why is the Subtropical Gyre Tilted?}

[96] In this work, we have thought of the Coral Sea in a Sverdrupian context with its Island Rule generalization. Sverdrup dynamics utilize the great simplification of topto-bottom vertical integration, but these ideas can be extended to an isopycnal layer framework that provides additional insight into the vertical structure of a subtropical gyre. Luyten-Pedlosky-Stommel [Luyten et al., 1983, hereafter LPS] models distribute the wind-driven Sverdrup transport over layers constrained to conserve potential vorticity (PV). They postulate that wind stress curl establishes the PV of upper layer water columns while they are exposed to the atmosphere, with those values conserved after the column is subducted into the gyre circulation.

[97] While the simplest baroclinic interpretation of a Sverdrupian subtropical gyre driven by downwelling wind stress curl is a bowl of isopycnals defining a single active layer, the LPS view extends this to a second, deeper, layer. Subduction occurs where each isopycnal outcrops at the poleward edges of the gyre, forming a ventilated subsurface layer under part of the upper layer gyre. The subducted water columns carry the surface-forced downwelling signal into the second layer, communicating it westward and equatorward along PV-conserving Rossby wave ray paths (LPS) [Luyten and Stommel, 1986; McCreary and Lu, 1994]. The result is a deepening of the lower interface, forming a secondary bowl of isopycnals below the initial single active layer bowl. Because the subduction signal originates at the poleward side of the gyre and propagates equatorward only slowly, this second bowl is shifted poleward from that in the upper layer, and the combination makes a tilted gyre, as suggested by the slopes in Figure 5 where the deepest point of each isotherm or isopycnal is further south than that of the one above.

[98] The geostrophic flow is anticyclonic in both layers of such a gyre, but the poleward shift of the lower layer bowl gives a band across the center of the gyre where the lower flow is westward but the upper is eastward; note that the upper layer eastward flow in this band is enhanced so the vertically integrated transport remains Sverdrupian. That is the situation in the western South Pacific from about $30^{\circ} \mathrm{S}$ to $15^{\circ} \mathrm{S}$, where the upper eastward flow is often called the Subtropical Countercurrent [Qiu, 1999; Qiu et al., 2008]. Thus conditions at the outcrops where subduction occurs - especially in spring when the deep winter mixed layer becomes isolated from the atmosphere as the surface restratifies - are crucial in determining the shape and characteristics of the gyre.

[99] Huang and Qiu [1998] performed an LPS calculation for the South Pacific forced by climatological winds [also see de Szoeke, 1987]. They noted the very deep late winter mixed layer along the subpolar front (between $40^{\circ} \mathrm{S}$ and $50^{\circ} \mathrm{S}$ ), where the sharp meridional gradient of outcropping isopycnals allows subduction and ventilation to at least sigma 27, contrasting with the North Pacific where the outcrops occur at warmer temperatures. This has two important consequences from the LPS point of view: first, the South Pacific wind-driven gyre extends very deep. The $1500 \mathrm{~m}$ depth extent of the NCJ noted here as well as by other observational studies [Gourdeau et al., 2008; Ganachaud et al., 2010; Gasparin et al., 2011] can be seen as due to the influence of the subpolar front, carried to the subtropics by equatorward flow in subsurface layers. Second, the strong tilt of the South Pacific subtropical gyre is implied by the ventilation of a larger range of isopycnals than in the North Pacific. The strong tilt results in more shear between the upper and lower layers and thus a broad latitude band where eastward surface currents overlie deeper westward flow. In turn, these vertically sheared zonal currents contribute to the tilted bifurcation of the western boundary current system by their pattern of inflow and outflow to the boundary layer.

\subsection{Remaining Open Questions}

[100] This work leaves several important observational and dynamical questions that could not be answered from the present data, and that present fruitful topics for further research.

\subsubsection{The "Direct" Inflow from the Northern Coral Sea to the Solomon Sea}

[101] The observations presented here show that a substantial portion of the shallow North Vanuatu Jet turns north into the Solomon Sea before reaching the coast of Australia. This is attested to by several pieces of evidence: first, a high-salinity tongue on sigma 24.5 (about $150 \mathrm{~m}$ depth in this region) extends into the Solomon Sea east of the western boundary current (Figure 8a); second, glider observations show the correspondence of the high salinity that marks the $\mathrm{NVJ}$ along $163^{\circ} \mathrm{E}$ with that across the mouth of the Solomon Sea (Figure 9); third, the measured velocities on sigma 24.5 in the heart of this water mass break off near $156^{\circ} \mathrm{E}$ from the main NVJ inflow (Figure 10a).

[102] Inflow from the NVJ is consistent with the observed upward extension of the New Guinea Coastal Undercurrent maximum as it enters the Solomon Sea: from near $400 \mathrm{~m}$ south of the Louisade Archipelago to a much shallower value inside the Solomon Sea (compare Figures 13e and 13f), which is also the pattern seen in Vitiaz St. [Lindstrom et al., 1990]. Similar conclusions have been reached by others studying several different data sets [QL02; Cravatte et al., 2011; Gasparin et al., 2012; Davis et al., 2012; Hristova and Kessler, 2012] and in models [Kessler and Gourdeau, 2007; Melet et al., 2010]; this has been called the "direct" inflow to the Solomon Sea. Gasparin et al. [2012] estimated this element of equatorward transport at $7 \mathrm{~Sv}$ during a single cruise in August 2007; given our large uncertainties, that value is consistent with the results here. The issue is important because theory and repeat glider observations suggest this direct connection between the North Vanuatu Jet and Solomon Sea transport varies more quickly and substantially with changes of the ENSO cycle than the deeper western boundary connection [Davis et al., 2012; Kessler and Cravatte, 2013]. Thus the dynamics controlling this northward turn of the NVJ are key to understanding the link between 
the South Pacific and the equator, especially at annual and interannual time scales.

[103] It is not clear why this direct transport occurs at all, since the wind stress curl is strongly negative across the mouth of the Solomon Sea and remains so throughout the climatological annual cycle; thus the Sverdrup transport is southward (Figures $4 \mathrm{~b}$ and $4 \mathrm{c}$ ). But given the quite different data sets that have identified this flow over many years, it seems unlikely to be an artifact of inadequate sampling. As best we can tell, the direct inflow occurs far enough east and begins far enough south of the Louisiades that it is probably not simply a Sverdrupian western boundary response to the interior flow (Figure 10a) [see Cravatte et al., 2011; Gasparin et al., 2012; Davis et al., 2012; Hristova and Kessler, 2012]. Thus one is left to conclude either that a deeper balancing southward flow exists, that topographic effects turn the current northward (though this is not obvious in the nonlinear model experiments of Couvelard et al. [2008] that explored the role of topographic steering), or that another nonlinear process is responsible; perhaps that the northern edge of the North Vanuatu Jet "feels" the fast boundary current wrapping around the Louisiade Archipelago-about $100 \mathrm{~km}$ outward from the island chain itself-further south and east than the actual coastline.

[104] A coherent dynamical explication of the northward midbasin turn of the NVJ remains to be accomplished, and is essential to an understanding of the subtropicalequatorial connection.

\subsubsection{Southward Flow Exiting the Solomon Sea in the East}

[105] The observations presented here, like those of others, have shown a shallow southward flow exiting the eastern Solomon Sea (Figure 10a); vertical sections (not shown) show this current to be surface-intensified and concentrated above $200 \mathrm{~m}$. A similar current pattern was described from the ADCP compilation of Cravatte et al. [2011], synoptic cruise data of Gasparin et al. [2012], surface drifter observations of Hristova and Kessler [2012], and glider observations of Davis et al. [2012], possibly indicating a semipermanent cyclonic eddy filling the eastern Solomon Sea. Gasparin et al. [2012] suggested that the southward flow had entered the Solomon Sea from the north, presumably through Solomon Strait, but it also may be a recirculation of the direct inflow from the NVJ discussed above.

[106] Is this southward flow entering the Coral Sea from the north a consistent feature? What is the origin and destination of its transport? Is it an additional source of mass or property transport to the Coral Sea, or does it simply recirculate within the eastern Solomon Sea?

\subsubsection{A Western Boundary Current on the Eastern Side of the Queensland Plateau?}

[107] The North Caledonian Jet splits around the Queensland Plateau, about $100 \mathrm{~km}$ east of the Australian mainland at $15.5^{\circ}-18^{\circ} \mathrm{S}$ (section 4.2 ); most of the flow seemed to turn north, but we were unable to quantify the split or verify if flow east of the Plateau is boundary-current-like. Is there a double western boundary current east and west of the Plateau? Do they occur in the same depth ranges? Do they vary synchronously or at different time scales? Are there consequences for property transport and the redistribution of arriving properties along the western boundary?

\subsubsection{Eddies and Circulation in the Gulf of Papua}

[108] Strong eddies extend to at least $1000 \mathrm{~m}$ depth in the Gulf of Papua (Scully-Power [1973] and the Argo float trajectories noted in section 5.1.4), but the properties carried north by the GPC seem to pass through unaffected (note the similarity of the oxygen sections in Figures 14c$14 \mathrm{e})$. Is it true that these eddies do not accomplish significant mixing? Dynamically, do the eddies represent boundary current overshoot (section 3.2) or do they propagate into the Gulf from the east? Do they have a preferred size, direction of rotation, or time scale?

[109] The Gulf is a meeting place of water from the NCJ and part of the NVJ, with the westward inflow, northward boundary current, and eddy circulations occurring close to each other in a small region (Figure 10). It is likely that the strong seasonal and ENSO signals of the NVJ [Kessler and Cravatte, 2013] make this system quite variable. What observational tools are required to adequately sample this complex set of interactions? Can we test and trust model representations of it?

\subsubsection{What Causes the Great Depth of South Pacific Circulation?}

[110] We and others have noted the deep extension of westward currents in the South Pacific compared to other subtropical gyres (section 4.2), especially the NCJ, and cited the role of deep isopycnal outcropping at the subpolar front as in the LPS model of Huang and Qiu [1998]. Is this theory an adequate mechanism to distinguish the South Pacific from the other subtropical oceans? Does interannual, decadal or climate change variability at the front imply corresponding changes at depths to sigma 27 in the western gyre? Can this be tested from observations?

\subsubsection{How Can the Redistribution of the SEC be Measured?}

[111] We have described two main sources of Coral Sea inflow that are relatively well defined, but were not able to quantitatively specify the mass or property fluxes that turn poleward or equatorward (section 6.2). Quantifying this bifurcation, which is the final split of South Pacific subtropical gyre water, is the principal unsolved climate problem of the Coral Sea and was a primary aim of this study. In the end, despite being able to reference much of the geostrophic flow using Argo trajectories, we found that significant fractions of the transport occur close to coastlines and reefs, or over shallow topography; since these regions are sampled only sporadically, we were unable to make a credible estimate of the bifurcating transports. As the Argo time series lengthens, and with the aid of other broad-scale tools (e.g., satellite altimetry), the interior circulation will become adequately resolved and its sampling uncertainty better defined, but many of the boundary currents and jets will remain poorly observed by these networks. It is apparent that a quantitative description of the bifurcating mass and property transports will require specifically designed ongoing programs to measure the boundary currents and near-coastal jets, so developing these programs should be a priority. Several of these efforts are underway in the context of the SPICE program.

\section{Appendix A: Steps to Map the Argo Trajectories}

[112] Three-dimensional velocity fields were constructed according to the following steps: 
[113] 1. Argo trajectory, metafile and profile files were downloaded from the USGODAE Argo data browser (http://www.usgodae.org/cgi-bin/argo_select.pl), to obtain all floats that ever entered the region $140^{\circ} \mathrm{E}-180^{\circ} \mathrm{E}, 35^{\circ} \mathrm{S}-$ $7^{\circ} \mathrm{S}$, through May 2011. 208 floats were found, with a total of 15,574 dives in the Coral Sea region.

[114] 2. For each dive of each float, the parking depth and endpoint times and positions were determined from the trajectory, metafile and profile files, when available. Positions on land were discarded. A float might not drift at its assigned parking depth because it could be bouncing over shallow topography or have internal problems or inconsistent file information. We found that the grounded flags and cycle numbers in the trajectory files, which would have been very useful in this step, were inconsistent and could not be relied upon. In some cases, the parking depth could not be determined, in which case the assigned parking depth was assumed. Dives that had a parking depth determined in this manner at or deeper than Smith and Sandwell bathymetry at their location were discarded. Also, any floats with parking depths less than $800 \mathrm{~m}$ were discarded in this step. After 452 discards, a total of 15,122 usable dives were found.

[115] 3. Dive time and distance were estimated from the float's transmissions. Since a float typically does not dive immediately after its last transmission, nor transmit immediately after arriving at the surface, we tried to estimate the unsampled surface time and drift following Park et al. [2005]. However, fewer than half of the floats had the required time and pressure information in the trajectory files. Therefore we found the average unsampled surface time from the floats with this information $(\sim 2 \mathrm{~h}$ on each end), and applied it to all dives of all floats. (In fact, experiment showed that the final speeds were not sensitive to choices from 2 to $12 \mathrm{~h}$.)

[116] 4. Drift during ascent and descent were estimated. Again we attempted to follow Park et al. but for most floats the necessary information (time of start and end of ascent and descent) was missing. As for the surface time, we assumed the average over the floats with these values available $(12 \mathrm{~h})$. We used mean geostrophic shear relative to $1000 \mathrm{~m}$ from CARS over these average times to estimate the drift during ascent and descent. The Ekman transport could have been incorporated into the estimated ascent/ descent drifts, but its value was more than an order of magnitude smaller than the other uncertainties and was ignored.

[117] 5. All dives resulting from step 4 were visually checked for indications of errors (high speeds, large surface drifts, dive times longer than 12 days, etc.) All the raw velocities and trajectories were individually plotted and visually inspected, and 266 questionable dives removed (about $1.8 \%$ ), leaving 14,856 dives finally available for mapping.

[118] 6. For floats whose parking depth was not at 1000 $\mathrm{m}$, CARS mean geostrophic shear was used to "rereference" each dive to $1000 \mathrm{~m}$ (but note that individual dives with parking depths shallower than $800 \mathrm{~m}$ had been discarded in step 2 above).

[119] 7. Raw velocities were found from the resulting distance and time values.

[120] 8. Lagrangian zonal and meridional velocities at $1000 \mathrm{~m}$ were gridded independently to produce a mean cli- matological field on a $0.25^{\circ}$ longitude, $0.25^{\circ}$ latitude grid, using an optimal objective analysis method [De Mey and Menard, 1989]. This method gives a value of subsurface velocity at each grid point, using nearby data only. Around each grid point, data were mapped taking into account the spatial scales of the relevant dynamics. The decorrelation scales in the zonal and meridional directions are $50 \mathrm{~km}$ where data coverage was good, and $100 \mathrm{~km}$ where data coverage was weaker. The scales were also chosen to avoid mapping across islands or reefs. The gridding method gives, in addition to the interpolated velocities, a normalized error at each grid point allowing us to estimate the confidence we can place in the currents we observe. Only currents for which the error is less than $40 \%$ of the variance at that point were considered.

[121] 9. To reduce small-scale noise, the mapped velocities were smoothed in the direction of each vector by a Gaussian weighted average with $e$-folding scale of $100 \mathrm{~km}$.

[122] 10. The smoothed mapped $1000 \mathrm{~m}$ velocities were used as a reference for CARS climatological geostrophic shear (i.e., adding the mapped $1000 \mathrm{~m}$ velocities to CARS shear relative to $1000 \mathrm{~m}$ ), to give a three-dimensional velocity field from the surface to $2000 \mathrm{~m}$. Where bathymetry occurs above $1000 \mathrm{~m}$ (and thus there are no float trajectories to provide referencing), we used CARS geostrophy relative to the bottom. This was especially significant over the roughly $300 \mathrm{~m}$ deep Marion Plateau from $19^{\circ} \mathrm{S}$ to $21^{\circ} \mathrm{S}$ on the coast of Australia, where isopycnals slope upward to the coast and the geostrophic shear is thus strongly southward (Figure 6). This appears to be a reasonable choice since it connects regions of similar boundary transport at these depths to its north and south (Figure 10 or 12), however, there is no direct physical justification for this choice.

[123] 11. We note that steps 2-4 above required ad hoc assumptions about the parking depths, the times of leaving and arriving at the surface, and the ascent/descent times that will have introduced errors of unknown magnitude.

[124] Acknowledgments. The authors honor the many pioneering contributions of Klaus Wyrtki (1925-2013), who wrote the earliest syntheses of the oceanography of this region in the early 1960s that defined the problems we work on today. The present research was possible through the work of the International Argo Program and the national programs that contribute to it (http://www.argo.ucsd.edu), and the CARS compilation of hydrographic data (http://www.cmar/csiro.au/cars). The glider temperature and salinity data used to make Figure 9 were collected, quality controlled, and made available by the Scripps Consortium on the Oceans Role in Climate. This work was done in the context of the SPICE program, and the authors thank their colleagues in this program: Thierry Delcroix, Alexandre Ganachaud, Florent Gasparin, Lionel Gourdeau, Melanie Grenier, and Frédéric Marin, as well as Russ Davis and Greg Johnson, for many stimulating discussions. W.S.K. is grateful to LEGOS/OMP for funding to visit Toulouse in 2010 that gave the opportunity to begin this work (and was a glorious experience). This work is cofunded by the Agence Nationale de la Recherche (project ANR-09-BLAN-0233-01) and by INSU/ LEFE/IDAO project Solwara. This is PMEL contribution 4017.

\section{References}

Andrews, J. C., and S. Clegg (1989), Coral Sea circulation and transport deduced from modal information models, Deep Sea Res., Part A, 36, 957-974.

Bryan, K. (1963), A numerical investigation of a nonlinear model of a wind-driven ocean, J. Atmos. Sci., 20, 594-606.

Burrage, D. M. (1993), Coral Sea currents, Corella, J. Aust. Bird Stud. Assoc., 17, 135-145. 


\section{KESSLER AND CRAVATTE: MEAN CIRCULATION OF THE CORAL SEA}

Butt, J., and E. Lindstrom (1994), Currents off the east coast of New Ireland, Papua New Guinea, and their relevance to regional undercurrents in the western equatorial Pacific Ocean, J. Geophys. Res., 99(C6), $12,503-12,514$

Chelton, D. B., M. G. Schlax, M. H. Freilich, and R. F. Milliff (2004), Satellite measurements reveal persistent small-scale features in ocean winds, Science, 303, 978-983.

Chen, S. M., and B. Qiu (2004), Seasonal variability of the South Equatorial Countercurrent, J. Geophys. Res., 108, C08003, doi:10.1029/ 2003JC002243

Choukroun, S., P. V. Ridd, R. Brinkman, and L. I. W. McKinna (2010), Surface circulation in the western Coral Sea and residence times in the Great Barrier Reef, J. Geophys. Res., 115, C06013, doi:10.1029/ 2009JC005761.

Church, J. A. (1987), The East Australian Current adjacent to the Great Barrier Reef, Aust. J. Mar. Freshwater Res., 38, 671-683.

Church, J. A., and F. M. Boland (1983), A permanent undercurrent adjacent to the Great Barrier Reef, J. Phys. Oceanogr., 13, 1746-1749.

CLIVAR (2012), Naming a Western boundary current from Australia to the Solomon Sea, CLIVAR Newsletter Exchanges, 58, 28.

Couvelard, X., P. Marchesiello, L. Gourdeau, and J. Lefebvre (2008), Barotropic zonal jets induced by islands in the southwest Pacific, J. Phys Oceanogr., 38(10), 2185-2204.

Cravatte, S., A. Ganachaud, Q. Duong, W. S. Kessler, G. Eldin, and P. Dutrieux (2011), Observed circulation in the Solomon Sea from SADCP data, Prog. Oceanogr., 88(1-4), 116-130.

Cronin, M. F. (1996), Eddy-mean flow interaction in the Gulf Stream at $68^{\circ} \mathrm{W}$ : Part II. Eddy forcing on the time-mean flow, J. Phys. Oceanogr., 26, 2132-2151.

Davis, R. E., W. S. Kessler, and J. T. Sherman (2012), Gliders measure western boundary current transport from the South Pacific to the equator, J. Phys. Oceanogr., 42, 2001-2013.

De Mey, P., and Y. Menard (1989), Synoptic analysis and dynamical adjustment of GEOS-3 and Seasat altimeter eddy fields in the northwest Atlantic, J. Geophys. Res., 94, 6221-6231.

De Szoeke, R. A. (1987), On the wind-driven circulation of the South Pacific Ocean, J. Phys. Oceanogr., 17, 613-630.

Delcroix, T., and C. Henin (1991), Seasonal and interannual variations of sea surface salinity in the tropical Pacific Ocean, J. Geophys. Res., 96(C12), 22,135-22,150.

Donguy, J.-R. (1994), Surface and subsurface salinity in the tropical Pacific Ocean relations with climate, Prog. Oceanogr., 34(1), 45-78.

Donguy, J.-R., and C. Henin (1977), On the origin of surface tropical water in the Tasman and Coral Seas, Aust. J. Mar. Freshwater Res., 28, 321-332.

Donguy, J.-R., C. OUdot, and F. Rougerie (1970), Circulation superficielle et subsuperficielle en mer du Corail et à $170^{\circ} \mathrm{E}, \mathrm{Cah}$. ORSTOM, Ser Océanogr., 8(1), 3-20.

Dunn, J. R., and K. R. Ridgway (2002), Mapping ocean properties in regions of complex topography, Deep-Sea Res. Part 1, 49, 591-604, doi : 10.1016/S0967-0637(01)00069-3.

Fine, R. A., R. Lukas, F. M. Bingham, M. J. Warner, and R. H. Gammon (1994), The western equatorial Pacific: A water mass crossroads, J. Geophys. Res., 99(C12), 25,063-25,080.

Firing, E., B. Qiu, and W. Miao (1999), Time-dependent Island Rule and its application to the time-varying North Hawaiian Ridge Current, $J$ Phys. Oceanogr., 29, 2671-2688.

Ganachaud, A., et al. (2007), Southwest Pacific Ocean circulation and climate experiment (SPICE)_Part II. Implementation Plan, NOAA OAR Special Report, 36 pp., Int. CLIVAR Proj. Off., CLIVAR Publ. Ser. 133, NOAA/OAR/PMEL, Seattle, Wash

Ganachaud, A., L. Gourdeau, and W. S. Kessler (2008), Bifurcation of the subtropical South Equatorial Current against New Caledonia in December 2004 from a hydrographic inverse box model, J. Phys. Oceanogr. 38(9), 2072-2084.

Gasparin, F., A. Ganachaud, and C. Maes (2011), A western boundary current east of New Caledonia), Observed characteristics, Deep Sea Res., Part 1 58(9), 956-969.

Gasparin, F., A. Ganachaud, C. Maes, F. Marin, and G. Eldin (2012), Oceanic transports through the Solomon Sea: The bend of the New Guinea Coastal Undercurrent, Geophys. Res. Lett., 39, L15608, doi:10.1029/ 2012 GL052575.

Godfrey, J. S. (1989), A Sverdrup model of the depth-integrated flow for the world ocean allowing for island circulations, Geophys. Astrophys Fluid Dyn., 45, 89-112.
Godfrey, J. S., and T. J. Golding (1981), The Sverdrup relation in the Indian Ocean, and the effect of Pacific-Indian Ocean throughflow on Indian Ocean circulation and on the East Australia Current, J. Phys. Oceanogr., $11,771-779$.

Godfrey, J. S., G. R. Cresswell, T. J. Golding, A. F. Pearce, and R. Boyd (1980), The separation of the East Australian Current, J. Phys. Oceanogr., 10, 430-440.

Gourdeau, L., W. S. Kessler, R. E. Davis, J. Sherman, C. Maes, and E. Kesternare (2008), Zonal jets entering the Coral Sea, J. Phys. Oceanogr., 38(3), 715-725.

Grenier, M., S. Cravatte, B. Blanke, C. Menkes, A. Koch-Larrouy, F. Durand, A. Melet, and C. Jeandel (2011), From the western boundary currents to the Pacific Equatorial Undercurrent: Modeled pathways and water mass evolutions, J. Geophys. Res., 116, C12044, doi:10.1029/ 2011JC007477.

Grenier, M., C. Jeandel, F. Lacan, D. Vance, C. Venchiarutti, A. Cros, and S. Cravatte (2013), From the subtropics to the central equatorial Pacific Ocean: Neodymium isotropic composition and rare earth element concentration variations, J. Geophys. Res., 118, 592-618, doi:10.1029/ 2012JC008239.

Hill, K. L., S. R. Rintoul, K. R. Ridgway, and P. R. Oke (2011), Decadal changes in the South Pacific western boundary current system revealed in observations and ocean state estimates, J. Geophys. Res., 116, C01009, doi:10.1029/2009JC005926.

Hristova, H. G., and W. S. Kessler (2012), Surface circulation in the Solomon Sea derived from Lagrangian drifter observations, J. Phys. Oceanogr., 42(3), 448-458.

Huang, R. X., and B. Qiu (1998), The structure of the wind-driven circulation in the subtropical Pacific Ocean, J. Phys. Oceanogr., 28, 1173-1186.

Kessler, W. S. (1999), Interannual variability of the subsurface high salinity tongue south of the equator at $165^{\circ} \mathrm{E}$, J. Phys. Oceanogr., 29(8), 20382049

Kessler, W. S., and S. Cravatte (2013), ENSO and short-term variability of the South Equatorial Current entering the Coral Sea, J. Phys. Oceanogr., 43, 956-969, doi:10.1175/JPO-D-12-0113.1.

Kessler, W. S., and L. Gourdeau (2007), The annual cycle of circulation in the southwest subtropical Pacific, analyzed in an ocean GCM, J. Phys. Oceanogr., 37(6), 1610-1627.

Lindstrom, E., R. Lukas, R. Fine, E. Firing, S. Godfrey, G. Meyers, and M. Tsuchiya (1987), The western equatorial Pacific ocean climate study, Nature, 330, 533-537.

Lindstrom, E., J. Butt, R. Lukas, and S. Godfrey (1990), The flow through Vitiaz Strait and St. George's Channel, Papua New Guinea, in The Physical Oceanography of Sea Straits, edited by L. Pratt, pp. 171-189, Kluwer Acad., Dordrecht, Netherland.

Luyten, J., and H. Stommel (1986), Gyres driven by combined wind and buoyancy flux, J. Phys. Oceanogr., 16, 1551-1560.

Luyten, J., Pedlosky, J., and H. Stommel (1983), The ventilated thermocline, J. Phys. Oceanogr., 13, 292-309.

Maes, C., L. Gourdeau, X. Couvelard, and A. Ganachaud (2007), What are the origins of the Antarctic Intermediate Waters transported by the North Caledonian Jet?, Geophys. Res. Lett., 34, L21608, doi:10.1029/ 2007 GL031546.

McCreary, J. P., and P. Lu (1994), Interaction between the subtropical and equatorial ocean circulations: The subtropical cell, J. Phys. Oceanogr., 24, 466-497.

McCreary, J. P., T. Miyama, R. Furue, T. Jensen, H.-W. Kang, B. Bang, and T. Qu (2007), Interactions between the Indonesian throughflow and circulations in the Indian and Pacific Oceans, Prog. Oceanogr., 75, 70114.

Melet, A., L. Gourdeau, W. S. Kessler, J. Verron, and J.-M. Molines (2010), Thermocline circulation in the Solomon Sea: A modeling study, J. Phys. Oceanogr., 40, 1302-1319.

Park, J. J., K. Kim, B. A. King, and S. C. Riser (2005), An advanced method to estimate deep currents from profiling floats, J. Atmos. Oceanic Technol., 22, 1294-1304.

Pedlosky, J. (1987), Geophysical Fluid Dynamics, 2nd ed, 710 pp., Springer-Verlag, New York.

Pedlosky, J., L. J. Pratt, M. A. Spall, and K. R. Helfrich (1997), Circulation around islands and ridges, J. Mar. Res., 55, 1199-1251.

Qiu, B. (1999), Seasonal eddy field modulation of the North Pacific Subtropical Countercurrent: TOPEX/Poseidon observations and theory, $J$. Phys. Oceanogr., 29(10), 2471-2486. 


\section{KESSLER AND CRAVATTE: MEAN CIRCULATION OF THE CORAL SEA}

Qiu, B., R. B. Scott, and S. Chen (2008), Length scales of eddy generation and nonlinear evolution of the seasonally modulated South Pacific Subtropical Countercurrent, J. Phys. Oceanogr., 38(7), 1515-1528.

Qiu, B., S. Chen, and W. S. Kessler (2009), Source of the 70-day mesoscale eddy variability in the Coral Sea and North Fiji Basin, J. Phys. Oceanogr., 39, 404-420.

Qu, T., and E. J. Lindstrom (2002), A climatological interpretation of the circulation in the western South Pacific, J. Phys. Oceanogr., 32(9), 2492-2508.

Qu, T., and E. J. Lindstrom (2004), Northward intrusion of Antarctic intermediate water in the western Pacific, J. Phys. Oceanogr., 34(9), 2104 2118

Qu, T., and R. Lukas (2003), The bifurcation of the North Equatorial Current in the Pacific, J. Phys. Oceanogr., 33, 5-18.

Qu, T., S. Gao, I. Fukumori, R. A. Fine, and E. J. Lindstrom (2008), Subduction of South Pacific waters, Geophys. Res. Lett., 35, L02610, doi 10.1029/2007GL032605.

Qu, T., S. Gao, I. Fukumori, R. A. Fine, and E. J. Lindstrom (2009), Origin and pathway of equatorial $13^{\circ} \mathrm{C}$ water in the Pacific identified by a simulated passive tracer and its adjoint, J. Phys. Oceanogr., 39(8), 1836-1853.

Reid, J. L. (1961), On the geostrophic flow at the surface of the Pacific Ocean with respect to the 1,000-decibar Surface, Tellus, 13(4), 489-502.

Ridgway, K. R., and J. R. Dunn (2003), Mesoscale structure of the mean East Australian Current System and its relationship with topography, Prog. Oceanogr., 56(2), 188-222.

Ridgway, K. R., and J. S. Godfrey (1994), Mass and heat budgets in the East Australian Current-A direct approach, J. Geophys. Res., 99(C2), 3231-3248

Ridgway, K. R., J. R. Dunn, and J. L. Wilkin (2002), Ocean interpolation by four-dimensional least squares-Application to the waters around Australasia, J. Atmos. Oceanic Technol., 19(9), 1357-1375.

Rochford, D. J. (1960), The intermediate depth waters of the Tasman and Coral Seas I. The $27.20 \sigma \mathrm{t}$ surface, Aust. J. Mar. Freshwater Res., 11 , 127-147.

Roemmich, D., and B. Cornuelle (1990), Observing the fluctuations of gyre-scale ocean circulation: A study of the subtropical South Pacific, $J$ Phys. Oceanogr., 20, 1919-1934.

Roemmich, D., and B. Cornuelle (1992), The subtropical mode waters of the South Pacific Ocean, J. Phys. Oceanogr., 22, 1178-1187.

Roemmich, D., and J. Gilson (2009), The 2004-2008 mean and annua cycle of temperature, salinity and steric height in the global ocean from the Argo program, Prog. Oceanogr., 82(2), 81-100.

Roemmich, D., J. Gilson, J. Willis, P. Sutton, and K. R. Ridgway (2005), Closing the time-varying mass and heat budgets for large ocean areas: The Tasman Box, J. Clim., 18, 2330-2343.

Roemmich, D., G. C. Johnson, S. Riser, R. Davis, J. Gilson, W. B. Owens, S. L. Garzoli, C. Schmid, and M. Ignaszewski (2009), The Argo program observing the global ocean with profiling floats, Oceanography, 22(2), 34-43, doi:10.5670/oceanog.2009.36.

Schiller, A., K. R. Ridgway, C. R. Steinberg, and P. R. Oke (2009), Dynamics of three anomalous SST events in the Coral Sea, Geophys. Res. Lett., 36, L06606, doi:10.1029/2008GL036997.

Scully-Power, P. D. (1973), Coral Sea flow budgets during winter, Aust. J. Mar. Freshwater Res., 24, 203-215.

Sokolov, S., and S. R. Rintoul (2000), Circulation and water masses of the southwest Pacific: WOCE section P11, Papua New Guinea to Tasmania, J. Mar. Res., 58, 223-268.

SPICE Community (2012), Naming a western boundary current from Australia to the Solomon Sea, CLIVAR Newsletter Exchanges, 58, 17(1), 28.

Stanton, B., D. Roemmich, and M. Kosro (2001), A shallow zonal jet south of Fiji, J. Phys. Oceanogr., 31, 3127-3130.

Thompson, R., and G. Veronis (1980), Transport calculations in the Coral and Tasman Seas, Deep Sea Res., Part A, 27, 303-323.

Tilburg, C. E., H. E. Hurlburt, J. J. O'Brien, and J. F. Shriver (2001), The dynamics of the East Australian Current system: The Tasman Front, the East Auckland Current, and the East Cape Current, J. Phys. Oceanogr., 31(10), 2917-2943.

Tomczak, M., and D. Hao (1989), Water masses in the thermocline of the Coral Sea, Deep Sea Res., Part A, 36(10), 1503-1514.

Tsuchiya, M. (1981), The origin of the Pacific equatorial $13^{\circ} \mathrm{C}$ water, $J$. Phys. Oceanogr., 11, 794-812.

Tsuchiya, M., R. Lukas, R. A. Fine, E. Firing, and E. Lindstrom (1989), Source waters of the Pacific equatorial undercurrent, Prog. Oceanogr., 23(2), 101-147

Veronis, G. (1966), Wind-driven ocean circulation-Part 2. Numerical simulations of the non-linear problem, Deep Sea Res. Oceanogr. Abstr., 13(1), 30-35

Wajsowicz, R. C. (1993), The circulation of the depth-integrated flow around an island with application to the Indonesian Throughflow, $J$. Phys. Oceanogr., 23, 1470-1484.

Webb, D. (2000), Evidence for shallow zonal jets in the South Equatorial Current region of the southwest Pacific, J. Phys. Oceanogr., 30, 706720.

Wunsch, C. (1978), Determining the general circulation of the oceans: A preliminary discussion, Science, 196, 871-875.

Wyrtki, K. (1960), The surface circulation in the Coral and Tasman Seas, Tech. Pap. 8, Commonwealth Sci. and Ind. Res. Organ., Div. of Fish. and Oceanogr., Cronulla, Australia.

Wyrtki, K. (1962a), The subsurface water masses in the western South Pacific Ocean, Aust. J. Mar. Freshwater Res., 13, 18-47.

Wyrtki, K. (1962b), Geopotential topographies and associated circulation in the western South Pacific Ocean, Aust. J. Mar. Freshwater Res., 13, $89-105$. 